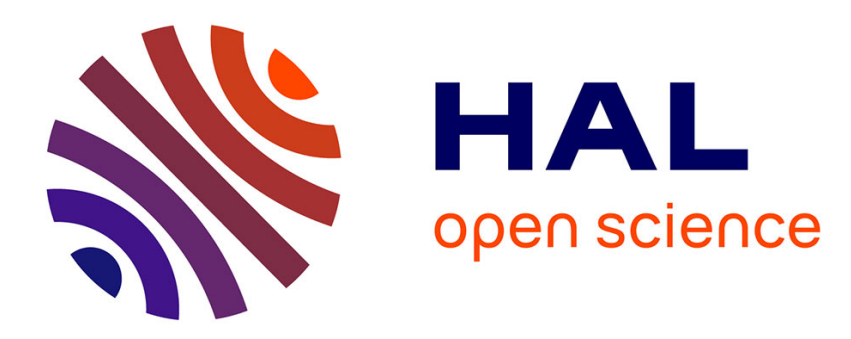

\title{
A review of biomedical multiphoton microscopy and its laser sources
}

\author{
Claire Lefort
}

\section{To cite this version:}

Claire Lefort. A review of biomedical multiphoton microscopy and its laser sources. Journal of Physics D: Applied Physics, 2017, 50 (42), pp.423001. 10.1088/1361-6463/aa8050 . hal-02481431

\section{HAL Id: hal-02481431 \\ https://hal.science/hal-02481431}

Submitted on 17 Feb 2020

HAL is a multi-disciplinary open access archive for the deposit and dissemination of scientific research documents, whether they are published or not. The documents may come from teaching and research institutions in France or abroad, or from public or private research centers.
L'archive ouverte pluridisciplinaire HAL, est destinée au dépôt et à la diffusion de documents scientifiques de niveau recherche, publiés ou non, émanant des établissements d'enseignement et de recherche français ou étrangers, des laboratoires publics ou privés. 


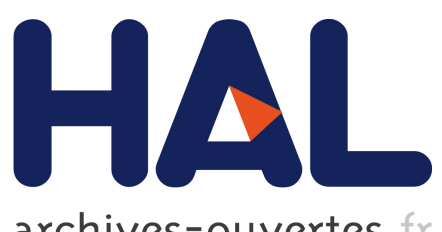

archives-ouvertes

\title{
A review of biomedical multiphoton microscopy and its laser sources
}

\author{
Claire Lefort
}

\section{To cite this version:}

Claire Lefort. A review of biomedical multiphoton microscopy and its laser sources. Journal of Physics D: Applied Physics, IOP Publishing, 2017, 50 (42), pp.423001. 10.1088/1361-6463/aa8050 . hal-02481431

\section{HAL Id: hal-02481431 \\ https://hal.archives-ouvertes.fr/hal-02481431}

Submitted on 17 Feb 2020

HAL is a multi-disciplinary open access archive for the deposit and dissemination of scientific research documents, whether they are published or not. The documents may come from teaching and research institutions in France or abroad, or from public or private research centers.
L'archive ouverte pluridisciplinaire HAL, est destinée au dépôt et à la diffusion de documents scientifiques de niveau recherche, publiés ou non, émanant des établissements d'enseignement et de recherche français ou étrangers, des laboratoires publics ou privés. 


\title{
A review of biomedical multiphoton microscopy and its laser sources
}

\author{
Claire Lefort \\ CNRS, Université de Limoges, UMR 7252, 123 avenue Albert Thomas, 87000 Limoges, France \\ E-mail: claire.lefort@xlim.fr \\ Received 16 September 2016, revised 10 July 2017 \\ Accepted for publication 18 July 2017 \\ Published

\begin{abstract}
Multiphoton microscopy (MPM) has been the subject of major development efforts for about 25 years for imaging biological specimens at micron scale and presented as an elegant alternative to classical fluorescence methods such as confocal microscopy. In this topical review, the main interests and technical requirements of MPM are addressed with a focus on the crucial role of excitation source for optimization of multiphoton processes. Then, an overview of the different sources successfully demonstrated in literature for MPM is presented, and their physical parameters are inventoried. A classification of these sources in function with their ability to optimize multiphoton processes is proposed, following a protocol found in literature. Starting from these considerations, a suggestion of a possible identikit of the ideal laser source for MPM concludes this topical review.
\end{abstract}

Keywords: biomedical multiphoton microscopy, two photon fluorescence, three photon fluorescence, second harmonic generation, third harmonic generation, comparison of laser sources, score and pondered score

(Some figures may appear in colour only in the online journal)

\section{Context of multiphoton microscopy (MPM)}

In the infinite universe of biomedical discoveries, the development of high-performance microscopes is crucial. The needs of microscopic characterization of biological specimens have become more and more precise, deep, diverse and fast [1]. Among all of the existing methods of microscopy, optical microscopy pertains to those compatible with living sample imaging, or in vivo studies without sample destruction. Various kinds of light-tissue interaction can occur, and constitute an immense field of scientific knowledge and research. Light probes the medium in a minimally invasive manner, where an incident photon on a biological sample can be absorbed, scattered or transmitted. Different information about pathologies or physiology of tissues can be deduced depending on the characteristics of the response. In this context, MPM has been the subject of major development efforts for about 25 years [2] as an essential tool able to generate optical biopsies where conventional light microscopes have revealed their limits. For example, confocal microscopy [3,4] is a traditional optical method adapted for imaging biological samples at micron scale, labelled or not, in vivo or ex vivo. Its principle is based on one-photon fluorescence (OPF) where incident light intensity is linearly dependent with fluorescence intensity emitted. But it presents a low level of beam penetration depth, uses a highly energetic excitation beam provoking non-negligible photodamage, and OPF is the exclusive modality of imaging available. Thus, MPM appeared as an elegant alternative with technical advantages [4, 5-11]: higher beam penetration depth, 3D imaging thanks to optical sectioning, decreased outof-focus background, photodamage restricted to focal point, better signal-to-noise ratio, excitation of UV-absorbing dyes, multiple imaging processes, technically simpler (no confocal pinhole required), etc.

In 1999, two groups reviewed the growing interest of MPM $[12,13]$ and identified an obstacle to its development in the

\begin{tabular}{|llllll}
\hline JNL:JPD & PIPS: AA8050 TS: NEWGEN & DATE:8/9/17 & EDITOR: IOP & SPELLING: US \\
\hline
\end{tabular}




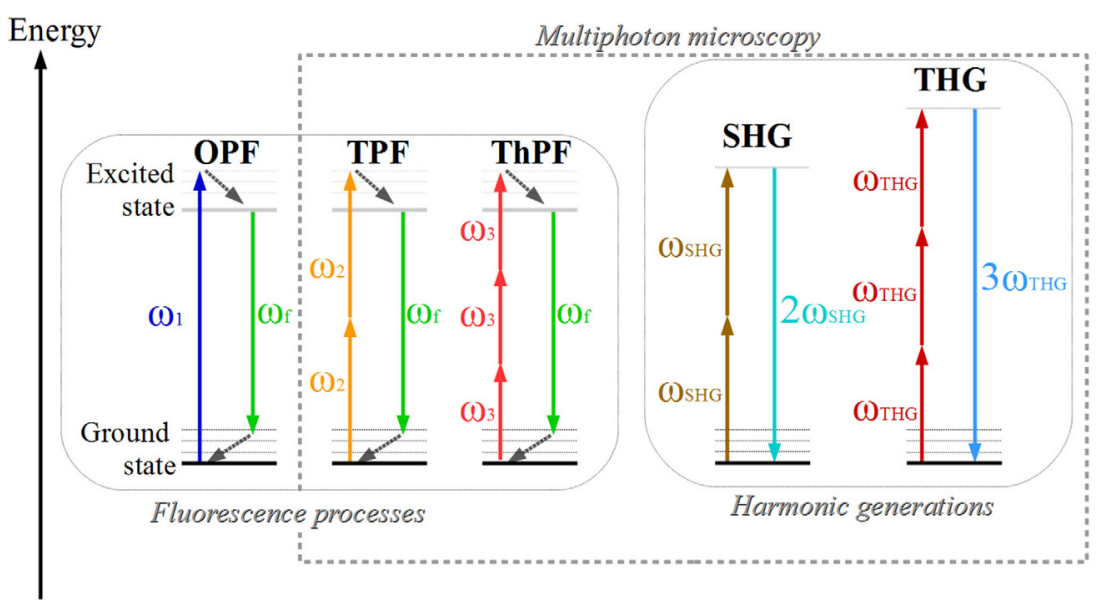

Figure 1. Jablonski diagrams of one-, two- and three-photon fluorescence and second and third harmonic generation.

exorbitant cost and complexity of laser sources required. At that time, they estimated that 'appropriate turn-key lasers have now been introduced, and their cost should decrease'. Today, 18 years after this statement, no real evolution concerning that point is noticeable: expensive commercial laser sources (more than $100 \mathrm{k} €$ ) are often implemented on multiphoton microscopes, which represent its first expenditure. The discussion about the best excitation source technically applicable to MPM, and judiciously or reasonably expensive, is still in the spotlight. Since 1995, several articles have proposed an overview of laser sources currently demonstrated for MPM with their technical specificities $[6,9,14-20]$. But the evolution of laser technologies or recent uses of old laser technologies for MPM justify the need for an updated review about laser sources employed for MPM. To go further than a simple list, a commentary concerning the more or less good compatibility of each source with biomedical MPM is discussed, following a protocol suggested in literature.

To address this subject, theoretical and technical requirements of MPM are first exposited. The context of application of MPM for biological and medical discoveries is then illustrated, and the substantial role of the excitation source is highlighted. Then, a review of the excitation sources already demonstrated in MPM is presented, with a classification of the compatibility of each of them with this application. All of these points allow proposing a possible identikit for the ideal excitation source for MPM.

\subsection{Theory of multiphoton processes and technical requirements for biomedical MPM}

1.1.1. Multiphoton processes involved in multiphoton imaging modalities. Processes involved in MPM are based on high-order nonlinear light-matter interactions, where multiple photons are required for contrast generation. MPM is characterized by an optical emission which has a quadratic or higher-order dependence on excitation power. MPM is thus commonly called 'nonlinear microscopy'. Phenomena involved can be categorized as fluorescence, harmonic generation and vibrational scattering. Each of these is described by a Jablonski diagram. Two-photon fluorescence (TPF) is the most widespread multiphoton phenomenon involved in MPM, but other high-order processes also exist in MPM: second harmonic generation [21-23] (SHG), coherent control [24-26], three-photon fluorescence (ThPF) or four-photon fluorescence [27-32], four-wave mixing such as coherent anti-Stokes Raman scattering or stimulated Raman scattering (CARS/SRS) [33-39], and third or fourth harmonic generation [39-42], for example.

Shen described the theory of these processes [43] in 1984, in a work which was thoroughly reviewed 20 years later by Shen [44] and Boyd [45]. They rest on an interaction between sample and electric field strength $E$ from an intense laser beam. This light-matter interaction induces a macroscopic polarization $P$ of matter detailed by equation (1):

$$
P=P_{\mathrm{P}}+\varepsilon_{0}\left(\chi^{(1)} E+\chi^{(2)} E^{2}+\chi^{(3)} E^{3}+\ldots\right)
$$

$P_{\mathrm{p}}$ being the macroscopic permanent polarization, $\varepsilon_{0}$ the vacuum permittivity, $\chi^{(\mathrm{i})}$ is a tensor which describes medium susceptibility. First order of susceptibility $\chi^{(1)}$ represents the refractive index of the medium, and contributes to the fluorescence imaging process. $\chi^{(2)}$ and $\chi^{(3)}$ are nonlinear tensors responsible for several nonlinear effects usually involved in MPM, such as harmonic generation, multiphoton fluorescence and four-wave mixing.

1.1.1. Multiphoton fluorescence. Several references in literature precisely detail the principle of multiphoton fluorescence, involving the time-dependent Schrödinger equation and Hamiltonian. Interested readers can find this lecture in the excellent and highly rigorous 'Biomedical Photonics Handbook' [1]. A few fundamental points, indispensable for MPM, recalled here, illustrated by the Jablonski diagrams presented in figure 1 .

TPF results from the third-order of susceptibility of the fluorophore $\chi^{(3)}$. It relies on a first step of two-photon absorption (TPA). Historically, TPA was first theoretically predicted by Maria Goeppert-Mayer in the thirties [46], and experimentally highlighted 30 years later by Kaiser et al [47] in a crystal of $\mathrm{CaF}_{2}: \mathrm{Sm}^{2+}$. TPF has then been demonstrated 30 years 

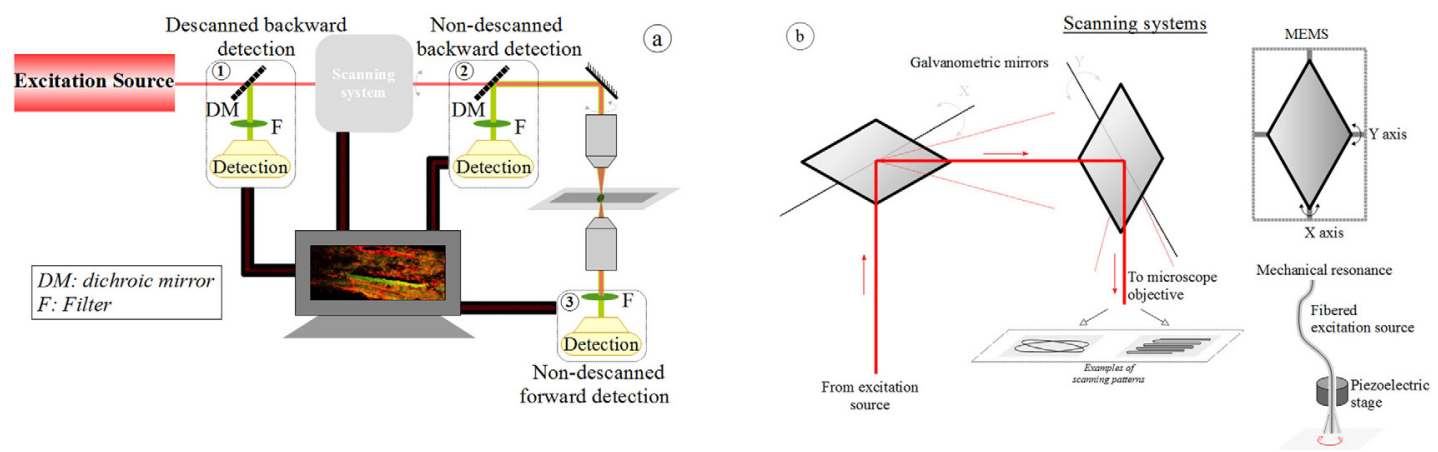

Figure 2. Structure of a multiphoton microscope. (a) General architecture; three possible positions for the detection device. (b) Example of three scanning systems: galvanometric, MEMS and PZT.

later by Webb's team on biological samples with two-photon imaging of chromosomes stained with a UV-excitable chromophore [2].

TPA happens when two identical photons are quasi-simultaneously absorbed by a fluorophore at sub-femtosecond scale $[1,5,12]$. When their combined energy is sufficient, and matches the energy gap between ground and excited states, a molecular transition to an excited electronic state occurs after reaching a virtual intermediate state. For each fluorophore, transition to an excited electronic state is possible only for an adapted spectral range of excitation, described by TPA cross sections or TPA spectra. In literature, several measures of two- or three-photon absorption cross sections of exogenous or endogenous fluorophores are centralized in high level publications [48-52].

Molecular transition can be induced by other combinations of photons, provided that the total energy is adapted to the energy gap of fluorophore: two photons not having exactly the same central wavelength [13], or a single photon, or threeor more-photons. Then a relaxation process occurs, consisting of a molecular transition back to the electronic ground state, joined with isotropic emission of a photon of fluorescence. This process is described by the Jablonski diagrams in figure 1 . The emission spectrum of a fluorescent substance is a function of its molecular constitution, and is independent of excitation wavelength as long as the latter lies within the excitation spectrum (Kasha's rule [53]). Each individual fluorophore has its own spectral properties depending on its chemical structure and environment. Emission spectrum is considered as similar whatever the mode of excitation with one, two or three photons; only its microenvironment, mainly polarity of solvent, can induce some modifications.

1.1.1.2. Harmonic generation. Harmonic generation is an instantaneous phenomenon of nonlinear coherent light scattering combining at least two photons and requiring phase-matching conditions [52]. The best known phenomenon is SHG, first proposed by Sheppard and Kompfner [54] in 1978, and demonstrated later by Freund et al [55]. This second-order nonlinear process happens when the medium involved presents a second order of susceptibility not equal to zero $\left(\chi^{(2)} \neq 0\right)$. This is produced exclusively in a medium where a breaking of symmetry exists, and is thus named 'noncentrosymmetric medium'. In contrast to multiphoton fluorescence, SHG happens without energy absorption: the energy of incident photons is scattered with a harmonic up-conversion. Consequently, a noncentrosymmetric structure under a laser light at frequency $\omega$ generates a harmonic at frequency $2 \omega$; this phenomenon is thus wavelength dependant. The emitted SHG is anisotropic, and propagates mainly in the forward direction, with a directionality tilted compared to the incident laser light path $[56,57]$. A second harmonic can also be generated in backward direction, with constraints on excitation characteristics depending on structural dimensions $[7,56,57]$; this imposes requirements to govern especially its (i) alignment compared to the sample, (ii) central wavelength and (iii) polarization. This point has a fundamental importance in MPM in the case of utilization for in vivo microscopy, where only backward SHG is possible.

Third harmonic generation (THG), more recently involved in MPM, is a third-order process requiring a condition of negative phase mismatch [58] only occurring in a nonhomogeneous medium. THG does not impose constraint on the symmetry of structure but occurs in a medium presenting rough parts in its refractive index or in its nonlinear susceptibility, for example. Conversely, no THG can happen in a homogeneous and isotropic medium; THG is known for the identification of interfaces between two media.

1.1.1.3. Raman scattering. Raman scattering is an inelastic phenomenon resulting from energy exchange between excitation photons and scattering molecules generating the vibration of chemical bonds [59]. Raman spectroscopy gives information about the density of chemical bonds of a single functional group. But weak, difficult to detect signals result from spontaneous Raman scattering. To improve it, CARS/SRS has been proposed [60, 61]. This multiphoton method consists of constraining the excitation of a specific chemical bond. Technically, it presents a major difference compared to multiphoton fluorescence or harmonic generation: a dual-color excitation (pump and Stokes waves) spatially and temporally superimposed is indispensible. Even if a commercial SRS setup is available (e.g. that from Invenio Imaging inc.), we can estimate that CARS/SRS is as yet only marginally involved in standard commercial multiphoton microscopes, and so will not be considered in this article.

1.1.2. Technical requirements for biomedical MPM. The structure of a multiphoton microscope is defined by physical 
Table 1. Usual excitation ranges for multiphoton processes and resulting emissions in the UV/visible range.

\begin{tabular}{lll}
\hline $\begin{array}{l}\text { Multiphoton } \\
\text { process }\end{array}$ & $\begin{array}{l}\text { Excitation } \\
\text { range }(\mu \mathrm{m})\end{array}$ & $\begin{array}{l}\text { Emission } \\
\text { range }(\mu \mathrm{m})\end{array}$ \\
\hline SHG & $0.8 \rightarrow 1.1$ & $0.4 \rightarrow 0.55$ \\
TPF & $0.6 \rightarrow 1.2$ & $0.3 \rightarrow 0.8$ \\
ThPF & $0.7 \rightarrow 1.9$ & $0.3 \rightarrow 0.8$ \\
THG & $1.2 \rightarrow 1.8$ & $0.4 \rightarrow 0.6$ \\
\hline
\end{tabular}

and technical principles involved for generation and detection of multiphoton processes. Some of these have a direct impact on the physical parameters of the excitation source. Here is a general overview of the technical requirements of MPM illustrated by figure 2. A focus on (i) excitation parameters (spectral range and bandwidth), (ii) spatiotemporal confinement of excitation and (iii) modes of detection and scanning are proposed.

\subsubsection{Excitation parameters: spectral ranges and bandwidths.}

1.1.2.1.1. Spectral ranges of excitation. In MPM, the adapted excitation spectrum depends on the probe imaged and the multiphoton process involved. By definition, the excitation beam has a longer spectral range than the emitted one (figure 1). Moreover, whatever the process involved in MPMfluorescence or harmonic generation-most of the targeted substances are emitting in the near UV or visible ranges, easily detectable. The excitation spectrum of MPM is consequently mainly in the near infrared range (NIR). Table 1 synthesizes excitation and emission spectral ranges usually found in MPM, depending on multiphoton process involved.

These spectral ranges constitute a major asset of MPM for tissue safety and penetration depth: the longest wavelengths are less energetic and damaging than the shortest; tissues are basically more transparent to infrared than visible light. This is due to the presence of absorbing constituents inside biological samples, such as water, hemoglobin or chromophore proteins. Ideal spectral windows have thus recently been identified $[1,62]$. Specific attention to these windows could allow extended penetration depth with limited photodamage.

1.1.2.1.2. Excitation spectral bandwidth. TPA cross sections of usual fluorophores are often ranked between 650 and $1000 \mathrm{~nm}$, and can be partially or sometimes totally superimposed. In standard multiphoton microscopes, the excitation spectral bandwidth is about a few nanometers at full width at half maximum (FWHM), and can be tuned. The simultaneous excitation of several fluorophores is thus possible if by chance parts of their TPA spectra are superimposed. But their simultaneous imaging by MPM is only possible if a part of the emission spectrum of each is independent from the others, allowing selective filtering and avoiding fluorescence crosstalk.

To circumvent this risk, two strategies exist. The first one consists of using two distinct multiphoton processes, such as TPF and SHG, with a single and short spectral bandwidth of excitation: the emitted beams are spectrally distinct by definition. But SHG is a phenomenon limited to specific structures (see section 1.1.1.2.). The second strategy, already demonstrated [63], consists of using a multiline laser or a wideband laser for imaging multiple fluorescent probes. Several spectral ranges of excitation can be simultaneously selected, facilitating simultaneous imaging of several fluorescent probes without fluorescence crosstalk.

\subsubsection{Excitation spatiotemporal confinement.}

\subsection{Spatiotemporal confinement of excitation and reso-} lution. The simultaneous spatiotemporal presence of several photons of excitation is indispensable for generating multiphoton processes. It is favored by their spatial and temporal confinements.

Spatial confinement is ensured by a focusing element. Outside the focal point, photon density is not high enough to generate multiphoton processes. Photodamage is consequently restricted to focal point. This major asset of MPM compared to confocal microscopy removes the necessity of implementing a confocal pinhole, making MPM confocal by definition. Usually in MPM the focalization is managed by a microscope objective. Its magnification and numerical aperture (NA) influence, respectively, the field of view (FOV) dimensions and resolution of images [64, 65].

The resolution is also governed by the dimensions of the interaction volume [15]. Considering this theory, a higherorder multiphoton process corresponds to a better resolution [66]. Following diffraction limited focusing properties, the resolution of TPF is theoretically about $0.5 \mu \mathrm{m}$ in a plane orthogonal to the optical axis $(X Y)$ and about $1 \mu \mathrm{m}$ in a plane along the optical axis ( $X Z$ or $Y Z$ ). Experimentally, it is more usual to find resolutions about $1 \mu \mathrm{m}$ in $X Y$ and several $\mu \mathrm{m}$ in $X Z$ or $Y Z$. For very high resolutions, some very sophisticated optical solutions exist, such as stimulated emission depletion (STED), saturated and/or structured illumination microscopy ( $S$ and/or SIM), etc, which are beyond the scope of this article. A complete presentation of these super-resolution techniques was published two years ago [67] in a topical review from Journal of Physics D: Applied Physics.

The temporal confinement of photons of excitation is favored either by an absolute high quantity of photons incoherent temporally or by a lowest quantity, temporally coherent and synchronized [68]. This last condition, possible thanks to pulsed lasers, is less energetic and damaging than the first one, ensured by continuous-wave (CW) lasers, which involves high average powers. The pulse duration is thus a fundamental consideration for optimizing multiphoton excitation. This point will be addressed in more detail in the second part of this article.

\subsubsection{Detection and scanning modes.}

1.1.2.3.1. Multiphoton detection. The strategy of detection is a fundamental point depending on features of the sample to be imaged. Two parameters of detection must be adjusted: position and technology of detection. If the sample is resected 
Table 2. Parameters of a multiphoton imaging constrained by LSM.

\begin{tabular}{lll}
\hline Parameter & $\begin{array}{l}\text { Direct user } \\
\text { adjustment }\end{array}$ & $\begin{array}{l}\text { Indirect } \\
\text { adjustment }\end{array}$ \\
\hline Laser repetition rate $f(\mathrm{~Hz})$ & No & No \\
Image size $\Omega_{\mathrm{iz}}$ (pixels) & Yes & No \\
Pixel dwell-time $\delta_{\mathrm{t}}(\mathrm{s} / \mathrm{pix})$ & Yes & No \\
Number of pulses per pixel $N_{\mathrm{pp}}$ & No & Yes, with $\delta_{\mathrm{t}}$ \\
Image rate $\varphi_{\mathrm{ps}}(\mathrm{fps})$ & No & Yes, with $\Omega_{\mathrm{i} z}$ \\
\hline
\end{tabular}

and thin, a multiphoton signal can be detected in the forward direction without disrupting scattering or absorption. This is represented by position 3 in figure 2(a). Moreover, this position is optimum for the detection of SHG and THG, which are anisotropic and preferentially emitted in the forward direction. But this organization is well adapted neither to imaging in vivo nor to thick specimens where only backward detection is accessible.

Concerning backward detection, descanned or non-descanned positions are possible, respectively illustrated by situations 1 and 2 (figure 2(a)). A non-descanned geometry enhances photon collection, and a photomultiplier tube (PMT) or an avalanche photodiode ideally cooled can detect even a single photon emitted from the sample. More usual PMTs, coupled with adapted filters whose characteristics can be adjusted in central wavelength, selectivity and spectral bandwidth, can detect the presence of multiphoton emission in the sub-microwatt range. But this emitted beam moves simultaneously with scan. By consequence, the descanned position is better adapted for spectral imaging involving a fixed spectrometer.

\subsection{Optical sectioning and laser scanning: $3 D$-image} reconstruction. Image formation is possible if the sample is moved under the excitation beam, or if the excitation spot is raster scanned across the area of interest with a pattern defined by the scanning mechanism. The latter strategy, faster than the former, is often chosen in commercial MPM. It produces a $2 \mathrm{D}$-image reconstructed point-by-point thanks to synchronization between scanning system and detection module. A 3D-image is reconstructed with a superimposition of 2D-images at different depth.

Several 2D-scanning systems exist, more or less fast, miniaturized, expensive and complex. The optimal model depends on the microscope architecture, speed and precision of scan required. The more widely implemented solution consists of two galvanometer mirrors [69] driven and synchronized electronically. As presented in figure 2, each mirror is mounted on a movable support rotating around an axis-respectively $X$ and $Y$ - with an angle defined as a function of the FOV required and the scan pattern chosen. Each mirror gives a 1D scan with an adjustable speed. One of the two galvanometer mirrors can be replaced by a resonant one, increasing scanning speed. When a high level of miniaturization is indispensable, some alternative strategies exist. A single mirror mounted on microelectromechanical systems (MEMS) has been successfully demonstrated for fiber-based multiphoton endoscopy [70, 71].
Table 3. Main physical features of excitation beam for optimal MPM.

\begin{tabular}{|c|c|}
\hline MPM characteristics & $\begin{array}{l}\text { Consequence on the properties } \\
\text { of the excitation beam }\end{array}$ \\
\hline $\begin{array}{l}\text { Multiphoton absorption/ } \\
\text { scattering }\end{array}$ & $\begin{array}{l}\text { Excitation wavelength in the } \\
\text { near infrared range }\end{array}$ \\
\hline Several modalities switchable & $\begin{array}{l}\text { Tunable central wavelength on } \\
\text { a wide spectral range }\end{array}$ \\
\hline $\begin{array}{l}\text { Broad spectral bandwidth of } \\
\text { absorption }\end{array}$ & Adjustable spectral bandwidth \\
\hline Temporal confinement & Pulsed \\
\hline Backward detection & Tunable polarization \\
\hline Phenomena lowly probable & Peak-power in the $\mathrm{kW}$ range \\
\hline $\begin{array}{l}\text { Laser scanning method (at least } \\
2 \mathrm{fps} \text { ) }\end{array}$ & $\begin{array}{l}\text { Repetition rate in the } \mathrm{MHz} \\
\text { range }\end{array}$ \\
\hline
\end{tabular}

For endomicroscopy, a piezoelectric tube fixed at the fiber tip is frequently presented [72]; the fiber tip is mechanically shaken with an amplitude provoking its mechanical resonance with a spiral pattern.

A scan in depth, usually named ' $Z$-scan' is then required to obtain a succession of 2D-images, which are then reconstructed in a volumetric 3D-image. This property is often managed by the vertical motion of the microscope objective or the sample holder having a sub-micrometric mechanical resolution. Alternatives for $Z$-scan have also been demonstrated. One of these takes advantage of the temporal dispersion induced by the optical elements of the microscope structure, such as lenses and microscope objective. The first one consists of generating spatial confinement with a highly dispersive lens. The central wavelength of excitation is then tuned over a range compatible with the absorption bandwidth of the fluorophore to be imaged [73]. Thus, the focal point is moved axially for each spectral bandwidth. The second approach consists of tuning the second order of dispersion (SOD) by a device placed before the microscope objective [74]. The temporal confinement is thus managed by the SOD, and adapted for different levels of depth. This method is named SSTF, for simultaneous spatial and temporal focusing, or SSFS, for soliton self-frequency shift $[75,76]$.

1.1.2.4. Consequences of laser-scanning method (LSM). In MPM, LSM constrains several image parameters, which must be correctly adjusted to avoid imaging mistakes such as 'ghost' pixels where no multiphoton signal is detected on several pixels due to technical limitations (and not to specificities of the sample imaged). Table 2 resumes the physical parameters of a multiphoton microscope concerned by this specific attention.

The combination of image size $\Omega_{\mathrm{i} z}$ (pixels) and pixel dwelltime $\delta_{\mathrm{t}}$ (s/pix) governs the frame rate $\varphi_{\mathrm{ps}}$ expressed in frame per second (fps) following equation (2):

$$
\delta_{\mathrm{t}}=\frac{1}{\Omega_{\mathrm{i} z} \varphi_{\mathrm{ps}}}=\frac{N_{\mathrm{pp}}}{f} .
$$

Laser repetition rate $f$ is often a fixed value. The combination of $\Omega_{\mathrm{i} z}$ and $\delta_{\mathrm{t}}$ must be limited by a bottom value resulting in at least one pulse per pixel, avoiding 'ghost' pixels. But with one 
pulse per pixel, image formation can potentially be sensitive to mis-synchronizations between repetition rate and scanning system. It is safer to choose a number of pulses per pixel at least equal to $N_{\mathrm{pp}}=2$. In that case, the number of excitation pulses is reduced at best to a minimum value, thus limiting superfluous excitation photons.

For example, for a laser repetition rate of $80 \mathrm{MHz}$, the fastest frame rate for an image size of $\Omega_{\mathrm{i} z}=512 \times 512$ pixels is $150 \mathrm{fps}$, resulting in a pixel dwell-time $\delta_{\mathrm{t}}=25 \mathrm{~ns} /$ pix for $N_{\mathrm{pp}}=2$. A galvanometric scanning system delivers, more usually, $\delta_{\mathrm{t}}=1 \mu \mathrm{s} /$ pix, resulting in $N_{\mathrm{pp}}=80 \mathrm{pulses} /$ pix. For such values of $\Omega_{\mathrm{iz} z}$ and $\delta_{\mathrm{t}}, N_{\mathrm{pp}}=2$ is within reach of a laser repetition rate of $2 \mathrm{MHz}$, and corresponds to $\varphi_{\mathrm{ps}}=4 \mathrm{fps}$

Now, let us consider in vivo measurements. In this case, a movie rate of $\varphi_{\mathrm{ps}}=16 \mathrm{fps}$ is more comfortable for live experiments. With $\delta_{\mathrm{t}}=1 \mu \mathrm{s} / \mathrm{pix}$ and $N_{\text {pp }}=2$ pulses/pix, the ideal excitation laser has a repetition rate $f=2 \mathrm{MHz}$ and image size $\Omega_{\mathrm{i} z}$ is reduced to $250 \times 250$ pixels. For a standard FOV of $500 \mu \mathrm{m} \times 500 \mu \mathrm{m}$, the $X Y$ resolution is consequently reduced to $2 \mu \mathrm{m}$ due to the laser scanning method, and no longer due to the physical principal of MPM presented above.

In conclusion, for each situation and depending on adjustable parameters, a compromise must be studied between frame rate $\varphi_{\mathrm{ps}}$, pixel dwell-time $\delta_{\mathrm{t}}$, FOV, resolution and laser repetition rate $f$. Moreover, a following section of this article will show that a slower repetition rate is better suited to generating TPF.

1.1.3. Summary of the parameters of the excitation source involved in MPM. Table 3 collects in a list the optimal parameters of the excitation source for MPM, based on its requirement highlighted in previous sections.

\subsection{MPM in biomedical imaging}

1.2.1. Label-free and multimodal imaging method with low energetic radiations. Thanks to its specific features exposed in the previous part and its technical simplicity compared to other methods such as CARS/SRS, STED or SIM, MPM has been profusely developed commercially. Comparing to classical one-photon-confocal microscopes working in the visible range, several advantages are linked to multiphoton technology which allows notably imaging living specimens at the micron scale with excitation wavelength in the NIR (lowly energetic) and without labeling.

Some substances naturally present in biological tissues at the intracellular scale and in the extracellular matrix are intrinsically fluorescent; they are named endogenous fluorophores. Despite their low quantum efficiencies, MPM is a label-free technique. Concerning the intracellular matrix, the most common endogenous fluorophores are nicotinamide adenine dinucleotide (NADH), a substance involved in intracellular redox
Table 4. Endogenous substances generating multiphoton processes.

\begin{tabular}{llll}
\hline Fluorophore & $\begin{array}{l}\text { Multiphoton } \\
\text { process }\end{array}$ & $\lambda_{\text {excitation }}(\mathrm{nm})$ & $\lambda_{\text {emission }}(\mathrm{nm})$ \\
\hline NADH & TPF & $650-800$ & $430-490$ \\
FAD & TPF & $700-1000$ & $490-650$ \\
Elastin & TPF & $750-870$ & $400-600$ \\
Collagen & TPF & $700-800$ & $450-600$ \\
Keratin & TPF & $760-860$ & $400-575$ \\
Myosin & SHG & $\lambda_{\text {excitation }}$ & $\lambda_{\text {excitation }} / 2$ \\
Collagen & SHG & $\lambda_{\text {excitation }}$ & $\lambda_{\text {excitation }} / 2$ \\
& & $(>800 \mathrm{~nm})$ & $(>400 \mathrm{~nm})$ \\
Lipids & THG & $\lambda_{\text {excitation }}$ & $\lambda_{\text {excitation }} / 3$ \\
\hline
\end{tabular}

metabolism, and flavoproteins such as flavin adenine dinucleotide (FAD), an endogenous marker of cellular metabolism. Concerning the extracellular matrix, elastin, collagen and keratin are also endogenous fluorophores. These substances are witnesses to physiological or morphological phenomena. The characterization of their absorption spectrum in one- or twophoton excitation has been reported in literature such as illustrated in [7, 49, 53, 77, 78].

The interest of imaging these substances by TPF, rather than OPF for example, has been presented in previous parts: higher beam penetration depth, decreased out-of-focus background, better signal to noise ratio, photodamage restricted to focal point, 3D imaging ... all of which has huge importance regarding microscopy for biomedical imaging.

Additionally to TPF, the use of a pulsed excitation in the NIR allows harmonic generation, another kind of imaging modality happening for specific kinds of tissue organisation (see section 1.1). Indeed, some biological constituents or tissues present structures compatible with SHG (noncentrosymmetric chiral crystalline organization) or THG (interfaces and inhomogeneities in the optical medium) [79]. The most noncentrosymmetric biological targets imaged by SHG are structures of collagen fibers, better known for their ability to generate SHG than to be fluorescent. Other structures have also been reported as good candidates for SHG: myosin fibers, tubulins and DNA. In those cases, SHG modality probes the macromolecular organization of these substances. THG is another modality of imaging, which has also been involved in biological MPM for imaging lipids or oxyhemoglobin but is also involved in the imaging of myosin or collagen [79]. Table 4 shows some example of endogenous substances generating multiphoton processes demonstrated in MPM.

1.2.2. Striking application of biomedical MPM. MPM is involved in many areas, from plant imaging [80] to pathology identification [81], oncology [82] and meat quality characterization [83]. Among these, the imaging of brain tissues to understand their functioning and to evaluate the impact of pharmacological or chemical treatments takes a prominent place. The early detection of cancerous sites and inflammatory markers in the body is also a major concern where MPM has been identified as an essential tool.

Currently, several strategies exist for the identification of pathologies such as cancers. The most widespread and reliable 

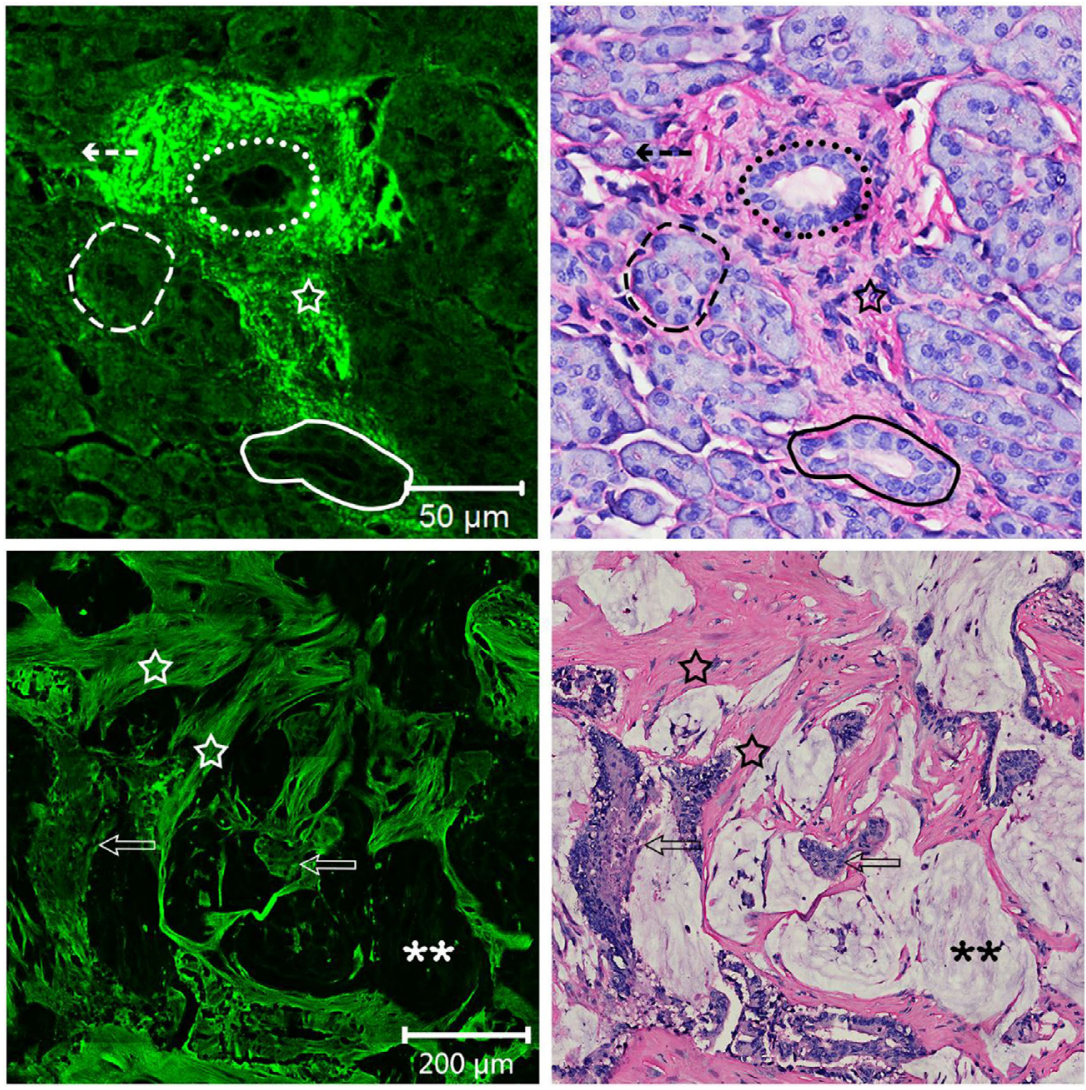

Figure 3. Comparison between multiphoton histology (left) and standard H\&E staining (right). Up: normal pancreatic tissue. Down: pancreatic colloid carcinoma. Reproduced with permission from [87].

involves a biopsy where the resected sample is labeled and analyzed by anatomopathologists $[84,85]$. To illustrate the essential role of MPM in medical discoveries, the example of multiphoton histology of cancerous tissues is chosen. Several groups have demonstrated that imaging the sample by MPM gives better image quality than routine labeling processes such as hematoxylin and eosin (H\&E) staining. A recent work by $\mathrm{Hu}$ and colleagues has demonstrated the value of MPM in the histology of pancreatic tissues, which present a structure composed by several endogenous optical biomarkers such as NADH (TPF), FAD (TPF) or collagen fiber (SHG) [86]. The MPM images restitute the same biological structure of tissue without labeling and with a better accuracy than standard hematoxylin and eosin (H\&E) labeling. In other words, MPM is a label-free method able to deliver histological images of resected samples having a subcellular resolution. Another group has demonstrated that MPM images clearly distinguish between structures of normal versus tumorigenic pancreatic tissues [87]. Figure 3 presents images of normal and deteriored pancreatic tissues imaged by MPM and by standard H\&E staining, extracted from [87] with author's and editor's reprint permissions. Thanks to the colocalization, it appears that unstained multiphoton images deliver similar information with a better resolution than H\&E staining.

Multiphoton histology presents four major advantages compared to standard histology. (i) It is label-free, (ii) with a subcellular resolution, (iii) 3D-images can be generated, and (iv) can potentially be performed in vivo thanks to multiphoton endomicroscopes now in development [70, 88]. These arguments taken together show MPM ready to be a diagnostic imaging modality and a major alternative to standard histological approaches-which must first be adopted by anatomopathologists.

\section{Laser sources implemented in MPM}

Today, laser sources implemented in standard commercial MPM are nearly all similar: a mode-locked femtosecond laser source delivering $10 \mathrm{~nm}$ of spectral width tunable between 700 and $1000 \mathrm{~nm}$. In this part, this source is first reviewed, with its complementary modules and its physical parameters. Starting from the identification of its limitations, alternative excitation sources found in the literature and developed especially for MPM are listed. A synthesis of their physical parameters is proposed.

\subsection{Laser technology usually implemented on commercial multiphoton microscopes}

Commercial turn-key solutions of multiphoton microscopes are proposed by companies such as Olympus, Nikon, Leica or Zeiss. They often include commercial elements for detection systems, scanning modules, optics and excitation laser sources.

For this last point, mode-locked titanium-doped sapphire laser [89-91] (Ti: Sa) is the technology most widely implemented in multiphoton microscopes. It is suited to a microscope workstation: reasonably (non-)voluminous, turnkey, 
user-friendly, stable and reliable. Its physical parameters fulfill the requirements of MPM listed in table 3: a pulse duration of 150 fs at the FWHM, with a repetition rate about 80 $\mathrm{MHz}$, a reserve of average power until several watts, a central wavelength tunable in the NIR between 700 and $1000 \mathrm{~nm}$, a peak-power around $100 \mathrm{~kW}$ with a linear polarization. Consequently, these sources, mainly commercialized by Coherent Inc. and Spectra-Physics, are today implemented deservedly on the overwhelming majority of commercial multiphoton microscopes. Pulse duration is sometimes modulated with the compensation of chromatic dispersion (Deep See ${ }^{\circledR}$, for example) occurring inside the microscope and based on more or less complex technologies, such as chirped mirrors [92], prism-line [93] or grism-based stretcher [94].

To access all modalities of MPM, especially THG or ThPF, a larger excitation range in the NIR is necessary (table 1). A solution commercially available consists in coupling a complementary module with the Ti: Sa source. This technique is based on parametric down conversions occurring into a birefringent nonlinear crystal. These optical parametric oscillators or amplifiers (OPO or OPA) convert the excitation wavelengths in longer wavelengths [95]. They are pumped by a Ti: Sa source, extending the range of excitation wavelengths available between $0.5 \mu \mathrm{m}$ up to about $2.5 \mu \mathrm{m}$ [96-98].

But covering the whole of this spectral range continuously requires the use of different kinds of OPOs or OPAs. These modules are particularly expensive $(\sim 100 \mathrm{k} €)$, and not adapted for simultaneous excitation with at least two spectral bandwidths: multispectral excitation is complex to implement with this method. Moreover, a Ti: Sa source presents a limited spectral bandwidth of $10 \mathrm{~nm}$ at FWHM. For example, in the case of multiphoton fluorescence, this spectral bandwidth gives access to the simultaneous imaging of two or three fluorophores at best, provided that (i) the TPA spectra have superimposed regions, (ii) the excitation spectrum is included in this superimposed region and (iii) the emission spectra have insulated parts free from crosstalk-being in this way compatible with individual detection.

In parallel, the development of alternative laser sources specially designed to substitute Ti: Sa sources in MPM based on alternative technologies has increased since the 2000s. The next part presents a list gathering the main excitation sources developed in the literature especially for MPM, except usual commercial solutions such as Ti: Sa sources and its complementary modules.

\subsection{Alternative laser sources demonstrated for biomedical MPM}

Thanks to the versatility of the technology involved, a huge number of sources can be created, having their own parameters: spectral range and bandwidth, pulse duration, repetition rate and average power. Several pulsed lasers are based on a gain medium included into a more or less complex optical setup coupled with a pumping element such as an external CW laser source for example. The detail of these technologies is beyond the scope of this article; interested readers have at their disposition several high level books or publications concerning this subject [19]. To summarize, this technology is based on a soliton-type pulse shaping: a precise combination of linear group-velocity dispersion and nonlinear self-phase modulation occurs inside the gain medium under the effect of the monochromatic CW source. Pulses are thus created, and can propagate without change. A crystal of sapphire, doped with titanium ions constitutes the gain medium of standard Ti: Sa sources implemented on MPM. Changing the crystal and the doping ions to other combinations give access to new spectral bandwidths. For example, two doping elements in a crystal structure are well-known for their emission in a spectral range between 1000 and $1100 \mathrm{~nm}$ : neodymium ions in a crystal of YAG, YLF or $\mathrm{YVO}_{4}$ [99] or ytterbium ions doping PCF [100].

Table 5 gathers the main laser sources especially developed and demonstrated in literature for MPM. They are organized, depending on pulse duration, into four categories: femtosecond, picosecond, nanosecond and CW. In the range of femtosecond durations, literature shows that solid-state systems and fibered systems are compatible with MPM and a high interest of wideband sources appeared in 2005 thanks to a femtosecond Ti: Sa source broadened into a PCF-which is not yet a commercial system. Parameters of commercial femtosecond Ti: Sa sources from Coherent Inc. and Spectra Physics usually implemented in multiphoton microscopes are reminded in table 5 and referenced with source $n^{\circ} 0$. Standard parameters are considered: $10 \mathrm{~nm}, 1 \mathrm{~W}, 80 \mathrm{MHz}, 150 \mathrm{fs}, 700-1000 \mathrm{~nm}$. Concerning picosecond and nanosecond sources for MPM, the majority of these result from the use of laser diodes which have fixed central wavelengths, spectral bandwidths, pulse durations and repetition rates.

Table 5 presents the panorama of the excitation sources which have so far been demonstrated in MPM in literature. The first consideration in studying this list is that each of them is adapted for biomedical MPM. But each situation is different, technically, in terms of physical parameters of the source, technology involved or application illustrations and fields. Judging such or such laser source better for MPM with only this table comes under clairvoyance. In order to classify them, and to identify the best one for MPM, or to depict its identikit, an objective comparison must be led first. This is the aim of the next part.

\section{Comparison of sources implemented for biomedical MPM}

\subsection{Theoretical elements of laser source comparison}

Efficiency of multiphoton processes is influenced by (i) focalization characteristics, (ii) characteristics of the biological sample imaged and (iii) excitation source and its parameters. A theory considered as a reference for the comparison of sources for MPM is precisely described by Webb et al [2, 14, 51], and is regularly recalled for pulsed lasers $[9,16,135,136$, $138,144]$, in the case of mode-locked systems or alternative technologies. This evaluation is based either on the estimation of the number of photons emitted by TPF or on the number of photons absorbed by TPA. Here, the time average 
fluorescence photon flux $F$ emitted by a fluorophore is chosen for the comparison. Table 6 reviews the experimental parameters influencing the emission of TPF and the related properties following Webb's theory.

The complete expression of $F$, such as described by Webb's team, respecting paraxial approximation [77], is:

$$
\begin{gathered}
F \approx \frac{1}{2} \phi \eta_{2} C \delta \frac{\xi}{f \tau} P_{0}^{2} \frac{8 n}{\pi \lambda}=k \frac{\xi}{f \tau} P_{0}^{2}=k S \\
k \approx \frac{1}{2} \phi \eta_{2} C \delta \frac{8 n}{\pi \lambda}
\end{gathered}
$$

with $k$ a constant defined by equation (4); $\xi=0.664$ for a Gaussian temporal profile and $\xi=0.588$ for a hyperbolicsecant square $\left(\operatorname{sech}^{2}\right)$ pulse.

Each excitation sources presented in table 5 has a specific combination of pulse duration $\tau$, average power $P_{0}$, central wavelength $\lambda$, spectral bandwidth $\Delta \lambda$ and repetition rate $f . S$ defined by equations (3) and (5) is only function with the physical parameters of the laser. It represents the score of the source, corresponding to its peak-power. A pondered score $P_{\mathrm{s}}$ is defined as follows, and treated in more detail in the next section.

$$
S=\xi \frac{P_{0}^{2}}{f \tau}=\xi P_{0}^{2} \times P_{\mathrm{S}} .
$$

For the comparison of laser sources gathered in table 5, we consider only the parameters linked with laser sources; fluorophore and microscope objective are fixed. Thus, theoretical bases for the optimization of TPF intensity with the excitation source are given, allowing the comparison of laser sources employed in MPM. For a higher order process such as three- or four-photon fluorescence, the multiphoton fluorescence intensity $S_{\alpha}$ is following equation (6), $\alpha$ being the number of photon absorbed for each photon of fluorescence emitted:

$$
S_{\alpha}=\frac{P^{\alpha}}{(f \tau)^{\alpha-1}} .
$$

\subsection{Comparison of laser sources}

3.2.1. Comparison with S score. The evolution of TPF intensity $F$ is described by equation (3). Considering $k$ as a constant (fluorophore and microscope objective fixed), $F$ is exclusively a function of the physical parameters of the laser: temporal pulse width $\tau$ and profile $\xi$, repetition rate $f$ and average power $P_{0}$. The evolution of $F$ is thus described by $S$, the score of the laser calculated for each source and gathered in table 5. This comparison can also be described with a 'figure-of-merit' (FOM) [145]. For a pulsed source, $F$ is linearly proportional to the peak power of the excitation source. But the information concerning the temporal pulse profile $\xi$ being seldom given, a compromise between a Gaussian and a sech ${ }^{2}$ profile is chosen for the comparison: $\xi=0.626$. In the specific case of a $\mathrm{CW}$ excitation, $\mathrm{Xu}$ et al [77] have considered the ratio $\xi /(f \tau)$ equal to 1 . When a laser parameter indispensible for the calculation of $S$ is missing, an estimated value written in italic is given, based on the elements found in the text.
3.2.2. Comparison with pondered score $P_{s}$. The score $S$ is proportional to $P_{0}^{2}$. Experimentally, the average power is quite easy to modify - for example with an optical density-and consequently distorts the relevance of the score $S$ : for identical $f$ and $\tau$, a higher average power is necessarily associated with a higher score. But in biomedical MPM, too high an average power might generate photodamages. This question is fundamental in MPM, and justifies a complete study by itself [146-148], which is beyond the scope of this article. To be free from this level-headedness, and for a visual classification of sources, a pondered score $P_{\mathrm{S}}$ is calculated by considering only $1 /(f \tau)$. For a better visualization, $P_{\mathrm{s}}$ values are normalized by the $P_{\mathrm{s}}$ value of source number 27, having a central place in the range of $P_{\mathrm{S}}$ values and consequently equal to 100 . Resulting values of $P_{\mathrm{s}}$ are named ' $P_{\mathrm{s} \text { norm' }}$ ' in table 5 .

For CW sources, the work of Hell et al [141] is followed. They explained that the value of such sources stands in the high number of excitation wavelengths available. They also reported that CW sources are approximately 200 times less good for MPM than standard Ti: Sa sources. Consequently, the $P_{\mathrm{S} \text { norm }}$ value for these sources is arbitrarily given as 0.01 . The comparison is visually highlighted by figure 4 , which plots the score of each source with their associated pondered value.

Figure 4 shows that for MPM and with the way of comparison chosen, femtosecond sources are well adapted and CW sources not. Between these two extrema, the use of a picosecond or a nanosecond source can present some interests or limitations. One of the laser source presented is undeniably better for MPM than the others. The source number 15, tested recently by Oshima et al [113], has a central wavelength of $1045 \mathrm{~nm}$ with very low average power of $0.6 \mathrm{~mW}$, repetition rate of $100 \mathrm{kHz}$ and pulse duration of $700 \mathrm{fs}$. That corresponds

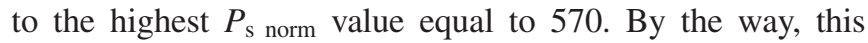
source looks the better among all sources already existing and tested for MPM, but has a very low repetition rate not very well suited to laser scanning MPM, as presented in section 1.1.2.

\section{Proposition of an identikit for the ideal laser source for MPM}

The principles of MPM have been presented in previous parts, with its related excitation sources. These objective statements make it possible now to have an opinion about what ideal laser source is better adapted for MPM. Forgetting all technical difficulties that can be encountered in laser source manufacturing, the purpose of this last section is to propose an identikit for the ideal physical parameters of the excitation source for MPM.

With a basic analysis of equation (5), the ideal excitation source has the highest average power possible, with the lowest pulse duration and the lowest repetition rate. But this primitive consideration must be pondered in light of the technical requirements of MPM reviewed in previous sections, as presented in following points.

\subsection{Repetition rate}

Considering equation (5), a slow repetition rate is favorable for MPM. But by definition, the repetition rate has a bottom value due to LSM of MPM. A standard image size of 
Table 5. Laser sources and their physical features employed in MPM. Wavelength conversion devices (conv. dev.) are often used for shifting the spectral bandwidth (PPLN, PCF...). Score $(S)$ and its pondered value $\left(P_{\mathrm{s}}\right)$ are defined in part 3.

\begin{tabular}{|c|c|c|c|c|c|c|c|c|c|c|c|c|}
\hline \multirow[b]{2}{*}{$\begin{array}{l}\text { Source } \\
n^{\circ}\end{array}$} & \multicolumn{2}{|c|}{ Laser system } & \multirow[b]{2}{*}{$\begin{array}{l}\Delta \lambda \\
(\mathrm{nm})\end{array}$} & \multirow[b]{2}{*}{$\begin{array}{l}P_{0} \max \\
(\mathrm{mW})\end{array}$} & \multirow[b]{2}{*}{$\begin{array}{l}f \\
(\mathrm{MHz})\end{array}$} & \multirow[b]{2}{*}{$\tau$} & \multirow[b]{2}{*}{$\lambda_{0}(\mathrm{~nm})$} & \multirow[b]{2}{*}{$\begin{array}{l}\text { Specimen } \\
\text { imaged }\end{array}$} & \multirow{2}{*}{$\begin{array}{l}\text { Mul- } \\
\text { tiphot. } \\
\text { process }\end{array}$} & \multirow[b]{2}{*}{ Ref } & \multirow[b]{2}{*}{$\mathrm{S}$} & \multirow[b]{2}{*}{$\begin{array}{l}P \mathrm{~S} \\
\text { norm }\end{array}$} \\
\hline & Gain media & $\begin{array}{l}\text { Conv. } \\
\text { dev. }\end{array}$ & & & & & & & & & & \\
\hline \multicolumn{13}{|c|}{ Femtosecond pulse duration } \\
\hline \multicolumn{13}{|c|}{ Solid-states systems } \\
\hline 0 & Ti: $\mathrm{Sa}$ & & 10 & 1000 & 80 & $150 \mathrm{fs}$ & $600-1000$ & & & & 52000 & 3.3 \\
\hline 1 & Nd:YLF & & & 300 & 123 & $300 \mathrm{fs}$ & 1047 & $\begin{array}{l}\text { Stained Caeno- } \\
\text { rhabditis elegans }\end{array}$ & ThPF & [99] & 1500 & 1.1 \\
\hline 2 & Cr:LiSrAlFl & & & 44 & 150 & $90 \mathrm{fs}$ & 860 & $\begin{array}{l}\mathrm{Ca}^{2+} \text { flows in } \\
\text { neurons }\end{array}$ & $\mathrm{TPF}$ & {$[101]$} & 90 & 3 \\
\hline 3 & Cr:forsterite & & 20 & 350 & 125 & $140 \mathrm{fs}$ & 1230 & Plant tissues & $\begin{array}{l}\text { SHG, } \\
\text { THG }\end{array}$ & {$[102]$} & 4400 & 2.3 \\
\hline 4 & Nd:YLF & $\times$ & & 53 & 120 & $99 \mathrm{fs}$ & $546-687$ & Muscle cell & TPF & {$[103]$} & 150 & 3.4 \\
\hline 6 & Cr:LiCAF & & 10.2 & 180 & 100 & $70 \mathrm{fs}$ & 800 & Brain vasculature & $\mathrm{TPF}$ & [105] & 2900 & 5.7 \\
\hline 7 & $\mathrm{Ti}: \mathrm{Sa}$ & & 10 & 3 & 22 & $300 \mathrm{fs}$ & $712-882$ & Mouse dorsal skin & $\mathrm{TPF}$ & {$[106]$} & 0.9 & 6.1 \\
\hline 8 & $\mathrm{Ti}: \mathrm{Sa}$ & $\times$ & 100 & & 76 & $10 \mathrm{fs}$ & $500-600$ & $\begin{array}{l}\text { Human skin } \\
\text { biopsies }\end{array}$ & $\begin{array}{l}\text { TPF, } \\
\text { SHG }\end{array}$ & [107] & 80 & 53 \\
\hline 9 & $\mathrm{Ti}: \mathrm{Sa}$ & $\times$ & 40 & 75 & 76 & $30 \mathrm{fs}$ & 800 & $\begin{array}{l}\text { Fluorescent probe } \\
\text { Rhodamine B }\end{array}$ & $\mathrm{TPF}$ & {$[108]$} & 1500 & 18 \\
\hline 10 & Ti: Sa & & 9.4 & 460 & 92 & $82 \mathrm{fs}$ & 784.5 & Labeled cells of & $\mathrm{TPF}$ & [109] & 18000 & 5.3 \\
\hline 11 & & & 10.2 & 350 & & $65 \mathrm{fs}$ & 807 & mouse intestine & SHG & & 13000 & 6.7 \\
\hline \multicolumn{13}{|c|}{ Fibered systems } \\
\hline$\overline{12}$ & Yb-Fiber & & & 200 & 39.2 & $40 \mathrm{fs}$ & 1060 & Human skin & THG & {$[110]$} & 16000 & 26 \\
\hline 13 & Yb-Fiber & & 200 & 380 & 3000 & $14 \mathrm{fs}$ & 850 & $\varnothing$ & $\varnothing$ & [111] & 2200 & 1 \\
\hline 14 & Yb-fiber & $\times$ & 17.6 & 92 & 34 & $118 \mathrm{fs}$ & 1040 & $\varnothing$ & $\varnothing$ & [112] & 1300 & 10 \\
\hline 15 & Yb-Fiber & & & 0.6 & 0.1 & $700 \mathrm{fs}$ & 1045 & $\begin{array}{l}\text { Spinal cord } \\
\text { transgenic mice }\end{array}$ & TPF & {$[113]$} & 3 & 570 \\
\hline & & & & & & & & $\begin{array}{l}\text { stained } \\
\text { human skin }\end{array}$ & $\mathrm{TPF}$ & & & \\
\hline 17 & Fibered laser & & & 10 & 50 & $100 \mathrm{fs}$ & 1562 & $\begin{array}{l}\text { Chloroplasts of } \\
\text { leaf }\end{array}$ & THG & {$[114]$} & 13 & 8 \\
\hline 18 & Er-doped fiber & $\times$ & & 80 & 67 & $150 \mathrm{fs}$ & 786 & Porcine skin & $\mathrm{TPF}$ & {$[71]$} & 400 & 4 \\
\hline 19 & Er-doped fiber & & & 30 & 50 & $150 \mathrm{fs}$ & 1560 & $\begin{array}{l}\text { Chlorophyll } \\
\text { from fresh leaf, } \\
\text { Drosophila, } \\
\text { zebra fish }\end{array}$ & $\begin{array}{l}\text { SHG } \\
\text { TPF } \\
\text { ThFP } \\
\text { THG }\end{array}$ & {$[115]$} & 75 & 5.3 \\
\hline 20 & $\begin{array}{l}\text { Er-doped } \\
\text { fiber }\end{array}$ & & & 70 & 8 & $100 \mathrm{fs}$ & $\begin{array}{l}1040 \\
\text { and } 1560\end{array}$ & $\begin{array}{l}\text { Pancreatic cancer } \\
\text { cell }\end{array}$ & $\mathrm{THG}$ & {$[116]$} & 3800 & 50 \\
\hline 21 & $\begin{array}{l}\text { fibre-based } \\
\text { fs laser }\end{array}$ & $\times$ & & 3 & 1 & $76 \mathrm{fs}$ & 1675 & $\begin{array}{l}\text { Labelled neurons } \\
\text { of sub-cortical } \\
\text { mouse brain }\end{array}$ & $\begin{array}{l}\text { TPF, } \\
\text { ThPF } \\
\text { THG }\end{array}$ & {$[30]$} & 74 & 530 \\
\hline \multicolumn{13}{|c|}{ Wideband systems } \\
\hline 22 & $\mathrm{Ti}: \mathrm{Sa}+\mathrm{PCF}$ & $x$ & 250 & 120 & 82 & $65 \mathrm{fs}$ & $700-950$ & $\begin{array}{l}\text { Stained pulmonary } \\
\text { artery }\end{array}$ & $\mathrm{TPF}$ & {$[117]$} & 1700 & 7.5 \\
\hline 23 & $\mathrm{Ti}: \mathrm{Sa}+\mathrm{PCF}$ & $\times$ & 220 & 53 & 80 & $270 \mathrm{fs}$ & $460-680$ & $\begin{array}{l}\text { Labelled nerves of } \\
\text { guinea pig }\end{array}$ & $\mathrm{TPF}$ & {$[118]$} & 81 & 1.9 \\
\hline 24 & $\mathrm{Ti}: \mathrm{Sa}+\mathrm{PCF}$ & $\times$ & 250 & 20 & 50 & $100 \mathrm{fs}$ & $850-1100$ & $\begin{array}{l}\text { Labeled endothe- } \\
\text { lial cell bovine } \\
\text { pulmonary artery }\end{array}$ & $\mathrm{TPF}$ & [119] & 50 & 8 \\
\hline 25 & $\mathrm{Ti}: \mathrm{Sa}+\mathrm{PCF}$ & $\times$ & 130 & 24 & 80 & $17.2 \mathrm{fs}$ & $750-880$ & Theoretically & $\mathrm{TPF}$ & {$[120]$} & 260 & 29 \\
\hline 26 & $\mathrm{Ti}: \mathrm{Sa}+\mathrm{PCF}$ & $\times$ & 100 & 1.5 & 76 & $110 \mathrm{fs}$ & $400-1500$ & Labeled proteins & $\mathrm{TPF}$ & {$[26]$} & 0.2 & 4.7 \\
\hline 27 & Ti:Sa + PCF & $x$ & 300 & 1 & 80 & $5 \mathrm{fs}$ & $600-1200$ & Labeled proteins & TPF & {$[121]$} & 1.6 & 100 \\
\hline 28 & $\mathrm{Ti}: \mathrm{Sa}+\mathrm{PCF}$ & $\times$ & 200 & 8 & 80 & $500 \mathrm{fs}$ & $550-750$ & $\begin{array}{l}\text { NADH } \\
\text { Tryptophan }\end{array}$ & TPF & [122] & 1 & 1 \\
\hline
\end{tabular}


Table 5. (Continued)

\begin{tabular}{|c|c|c|c|c|c|c|c|c|c|c|c|c|}
\hline \multirow[b]{2}{*}{$\begin{array}{l}\text { Source } \\
n^{\circ}\end{array}$} & \multicolumn{2}{|l|}{ Laser system } & \multirow[b]{2}{*}{$\begin{array}{l}\Delta \lambda \\
(\mathrm{nm})\end{array}$} & \multirow[b]{2}{*}{$\begin{array}{l}P_{0} \max \\
(\mathrm{mW})\end{array}$} & \multirow[b]{2}{*}{$\begin{array}{l}f \\
(\mathrm{MHz})\end{array}$} & \multirow[b]{2}{*}{$\tau$} & \multirow[b]{2}{*}{$\lambda_{0}(\mathrm{~nm})$} & \multirow[b]{2}{*}{$\begin{array}{l}\text { Specimen } \\
\text { imaged }\end{array}$} & \multirow{2}{*}{$\begin{array}{l}\text { Mul- } \\
\text { tiphot. } \\
\text { process }\end{array}$} & \multirow[b]{2}{*}{ Ref } & \multirow[b]{2}{*}{$\mathrm{S}$} & \multirow[b]{2}{*}{$\begin{array}{l}P \mathrm{~S} \\
\text { norm }\end{array}$} \\
\hline & Gain media & $\begin{array}{l}\text { Conv. } \\
\text { dev. }\end{array}$ & & & & & & & & & & \\
\hline 29 & Yb:KYW + PCF & $\times$ & 60 & 3.1 & 76 & $10 \mathrm{fs}$ & $900-1160$ & $\begin{array}{l}\text { Labeled } \\
\text { fibroblasts }\end{array}$ & TPF & [123] & 7.9 & 53 \\
\hline 30 & $\mathrm{Ti}: \mathrm{Sa}+\mathrm{PCF}$ & $\times$ & 200 & 7 & 80 & $57 \mathrm{fs}$ & 700-900 & Pulmonary cells & $\mathrm{TPF}$ & {$[124]$} & 6.7 & 8.8 \\
\hline 31 & $\begin{array}{l}\text { Yb- } \\
\text { fibered + PCF }\end{array}$ & $\times$ & 200 & 250 & 55 & $500 \mathrm{fs}$ & $600-800$ & $\begin{array}{l}\text { Blood vessels in } \\
\text { mouse brain, rat } \\
\text { tail tendon }\end{array}$ & $\begin{array}{l}\text { TPF } \\
\text { SHG }\end{array}$ & {$[125]$} & 1400 & 1.5 \\
\hline 32 & $\begin{array}{l}\text { Diode }+ \\
\text { Er-doped fiber }\end{array}$ & & 100 & 450 & 50 & $70 \mathrm{fs}$ & $1650-1750$ & $\begin{array}{l}\text { Labeled mouse } \\
\text { nervous tissue and } \\
\text { labeled } \\
\text { drosophila } \\
\text { embryos }\end{array}$ & $\begin{array}{l}\text { THG } \\
\text { ThPF }\end{array}$ & {$[126]$} & 36000 & 11 \\
\hline \multicolumn{13}{|c|}{ Picosecond pulse duration } \\
\hline$\overline{33}$ & $\begin{array}{l}\text { Nd: yttrium } \\
\text {-vanadate }\end{array}$ & & & 20 & 200 & $7.1 \mathrm{ps}$ & 1064 & Pollen grain & $\mathrm{TPF}$ & {$[127]$} & 0.2 & 0.03 \\
\hline 34 & $\begin{array}{l}\text { Nd: yttrium } \\
\text {-vanadate }\end{array}$ & & & 40 & 200 & $7 \mathrm{ps}$ & 1064 & Dyes & $\begin{array}{l}\text { TPF, } \\
\text { ThPF }\end{array}$ & {$[128]$} & 0.7 & 0.03 \\
\hline 35 & Laser diode & $\times$ & 2 & 98 & 500 & $5.2 \mathrm{ps}$ & 783 & $\begin{array}{l}\text { Stained } \\
\text { glomeruli, } \\
\text { tubules }\end{array}$ & $\mathrm{TPF}$ & [129] & 2.3 & 0.02 \\
\hline 36 & Laser diode & $\times$ & 1 & 20 & 200 & $5 \mathrm{ps}$ & 770 & Stained actin & $\mathrm{TPF}$ & {$[130]$} & 0.3 & 0.04 \\
\hline 37 & $\mathrm{Ti}: \mathrm{Sa}+\mathrm{PCF}$ & $x$ & 100 & 5 & 82 & $10 \mathrm{ps}$ & $500-600$ & Tryptophan & TPF & [131] & 0.02 & 0.05 \\
\hline 38 & Laser diode & & 2 & 50 & 10 & 3 ps & $\begin{array}{l}980 \text { and } \\
1030\end{array}$ & $\begin{array}{l}\text { Neurons } \\
\text { expressing GFP } \\
\text { and adipose } \\
\text { tissue }\end{array}$ & $\begin{array}{l}\text { TPF, } \\
\text { SHG, } \\
\text { SFG }\end{array}$ & {$[132]$} & 52 & 1.3 \\
\hline 39 & $\mathrm{Ti}: \mathrm{Sa}+\mathrm{PCF}$ & $\times$ & & 20 & 80 & $1.9 \mathrm{ps}$ & $750-1260$ & $\begin{array}{l}\text { Molecules form } \\
\text { leaf }\end{array}$ & $\mathrm{TPF}$ & {$[133]$} & 1.6 & 0.3 \\
\hline 40 & Laser diode & & & 174 & 20 & $5 \mathrm{ps}$ & 1030 & $\begin{array}{l}\text { In vivo labeled } \\
\text { hippocampal neu- } \\
\text { rons }\end{array}$ & $\mathrm{TPF}$ & {$[134]$} & 190 & 0.4 \\
\hline 41 & Laser diode & $\times$ & & 500 & 10 & $7.5 \mathrm{ps}$ & 1064 & $\begin{array}{l}\text { In vivo labeled } \\
\text { mouse brain }\end{array}$ & TPF & {$[135]$} & 2100 & 0.5 \\
\hline 42 & Laser diode & & 0.95 & 30 & 66.67 & $2.3 \mathrm{ps}$ & 976 & Labeled and & TPF & {$[136]$} & 3500 & 250 \\
\hline 43 & & & & 58 & 10 & & & $\begin{array}{l}\text { fixed mouse } \\
\text { brain tissue }\end{array}$ & & & 92 & 1.7 \\
\hline \multicolumn{13}{|c|}{ Nanosecond pulse duration } \\
\hline 44 & Nd:YAG & & 1 & 300 & 0.033 & $0.8 \mathrm{~ns}$ & 1064 & $\begin{array}{l}\text { Rat cornea } \\
\text { tissue }\end{array}$ & $\begin{array}{l}\text { TPF, } \\
\text { SHG, } \\
\text { ThPF }\end{array}$ & {$[137]$} & 2100 & 1.5 \\
\hline 45 & Laser diode & $\times$ & 1800 & 120 & 0.25 & $1 \mathrm{~ns}$ & $600-2400$ & Myosin, actin & $\begin{array}{l}\text { TPF, } \\
\text { SHG }\end{array}$ & {$[138]$} & 36 & 0.2 \\
\hline 46 & MOPA & & & 135 & 0.4 & $0.56 \mathrm{~ns}$ & $\begin{array}{l}1064 \\
1122 \\
1186 \\
\end{array}$ & Plant leaves & $\mathrm{TPF}$ & {$[139]$} & 51 & 0.2 \\
\hline \multicolumn{13}{|c|}{ CW excitation } \\
\hline 47 & $\mathrm{Nd}: Y A G$ & & 1 & 480 & $\varnothing$ & $\varnothing$ & 1064 & $\begin{array}{l}\text { Labeled latex } \\
\text { beads }\end{array}$ & TPF & {$[140]$} & 0.2 & 0.01 \\
\hline 48 & $\mathrm{ArKr}$ & & 1 & 200 & $\varnothing$ & $\varnothing$ & 647 & $\begin{array}{l}\text { Cell nuclei } \\
\text { DAPI }\end{array}$ & $\mathrm{TPF}$ & {$[141]$} & 0.04 & 0.01 \\
\hline 49 & Laser diode & & 1 & 130.8 & $\varnothing$ & $\varnothing$ & 830 & Cells e-GFP & $\mathrm{TPF}$ & [142] & 0.02 & 0.01 \\
\hline 50 & Kr-ion & & 1 & 100 & $\varnothing$ & $\varnothing$ & 647.1 & $\begin{array}{l}\text { Labeled HeLa } \\
\text { cells }\end{array}$ & $\mathrm{TPF}$ & [143] & 0.01 & 0.01 \\
\hline 51 & Laser diode & & 1 & 190 & $\varnothing$ & $\varnothing$ & 809 & $\begin{array}{l}\text { Stained T } \\
\text { lymphocytes }\end{array}$ & $\mathrm{TPF}$ & [144] & 0.04 & 0.01 \\
\hline
\end{tabular}


Table 6. Parameters influencing the emission of photons by TPF.

\begin{tabular}{|c|c|c|c|}
\hline $\begin{array}{l}\text { Element of the multiphoton } \\
\text { microscope }\end{array}$ & \multicolumn{2}{|c|}{ Parameter involved } & Parameter influencing multiphoton imaging \\
\hline \multirow[t]{4}{*}{ Microscope objective } & \multicolumn{2}{|l|}{ NA } & Spatial confinement of excitation photons \\
\hline & \multicolumn{2}{|c|}{ Magnification } & \\
\hline & \multirow{2}{*}{\multicolumn{2}{|c|}{$\begin{array}{l}\text { Fluorescence collection efficiency } \phi \\
\text { Wavelength transmission efficiency }\end{array}$}} & Collection efficiency \\
\hline & & & \\
\hline \multirow[t]{3}{*}{ Fluorophore } & \multicolumn{2}{|c|}{ TPA cross-section $\delta$} & TPA efficiency \\
\hline & \multirow{2}{*}{\multicolumn{2}{|c|}{$\begin{array}{l}\text { Fluorescence quantum efficiency } \eta_{2} \\
\text { Refractive index of sample medium } n \\
\text { Concentration } C\end{array}$}} & Absolute quantity of TPA processes \\
\hline & & & \\
\hline \multirow[t]{5}{*}{ Excitation source } & $f$ & Repetition rate & Temporal confinement of photons \\
\hline & $\tau$ & Temporal pulse width (FWHM) & Peak power \\
\hline & $P_{0}$ & Average power & \\
\hline & $\xi$ & Temporal pulse shape & \\
\hline & $\lambda$ & Central wavelength & \\
\hline
\end{tabular}

$512 \times 512$ pixels, with $1 \mu$ s/pixel and 2 pulses per pixel (see section 1.1.2.4), corresponds to an imaging speed of $\sim 2$ frames per second. With these parameters, the repetition rate of the ideal excitation source for MPM is about 2 MHz.

\subsection{Spectral range and bandwidth}

The score $S$ of the sources does not consider the impact of the spectral bandwidth $\Delta \lambda$ on the optimization of excitation processes. As related in the first part, the emission spectra of fluorophores are independent of the excitation wavelength: as long as the excitation wavelength is inside the TPA spectrum (Kasha's rule), the absorption and emission processes can occur. The excitation sources listed in table 5 often have a short spectral bandwidth $\Delta \lambda$ of few tens of nanometers at best. But with such a unique and short excitation bandwidth, fluorophores with highly distant TPA spectra cannot be imaged simultaneously. The possibility of multiplying the number of spectral bandwidths with tunable central wavelength and width is of first interest. This would generate a versatile excitation spectral bandwidth highly sought for MPM: whatever the fluorophore involved, the excitation spectrum can be adapted. The ideal excitation source for MPM might have multiple and tunable spectral bandwidths, on all the two- and three-photon absorption spectra of the common exogenous or endogenous fluorophores. This specific property permits the selection of several spectral bandwidths $\Delta \lambda$ of excitation compatible with the TPA spectrum of fluorophores imaged, each of them covering a minimum spectral width of a few $\mathrm{nm}$. The spectral bandwidths of the ideal source for MPM are multiples (multicolor) with adjustable width and tunable in central wavelength between $500 \mathrm{~nm}$ and $1.9 \mu \mathrm{m}$ (table 1).

\subsection{Pulse duration and profile}

Considering equation (5), short pulse durations with a Gaussian profile are ideal for MPM. More, TPA being a sub-femtosecond phenomenon, femtosecond pulse duration constitutes its bottom value. According to femtosecond pulse durations found in

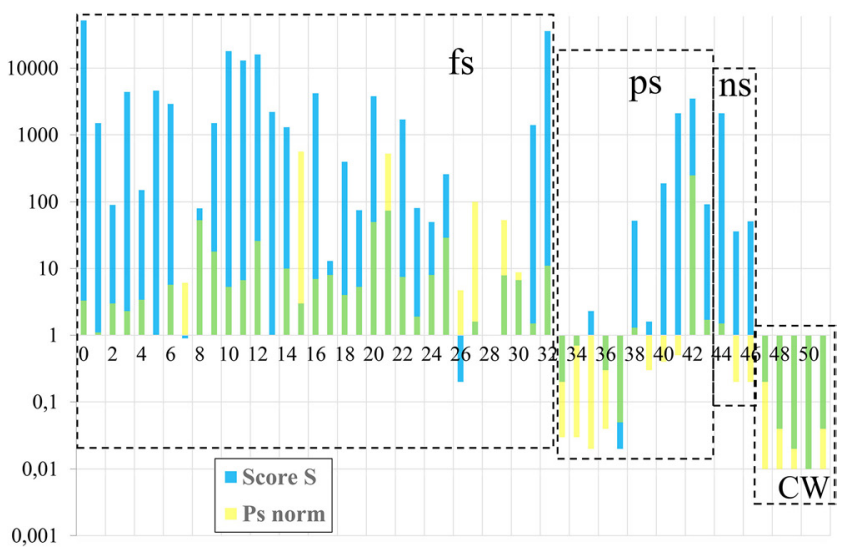

Figure 4. Graphical comparison of laser sources tested for MPM in the literature. Horizontal axis represents each source with its number attributed in table 3 . Score $S$ (blue) of each source and its pondered value (yellow) are plotted in a logarithm scale; a superimposition between $S$ and $P_{\text {s norm }}$ appears in green.

the literature (table 5) 5 fs FWHM generated by a mode-locked system seems the best. With such a short duration, the spectral bandwidth at $800 \mathrm{~nm}$ is at least $200 \mathrm{~nm}$ for perfectly compressed pulses (Fourier transform). Depending on TPA spectra, such a spectral bandwidth is often unnecessary in its totality. It is likely to result in photodamage or blur and noise in the resulting image. Reducing this value in order to adapt the spectral bandwidth to the TPA spectrum is necessarily associated with increased pulse duration. For example, $10 \mathrm{~nm}$ of spectral bandwidth corresponds to a pulse duration equal to 100 fs FWHM.

The relevance of mode-locked systems in MPM is thus in question. A proportion between pulse duration and spectral bandwidth is not adapted to a totally versatile system with a tunable central wavelength and adjustable spectral width. In the case of a multiphoton imaging of several fluorophores with TPA spectra broadened on a large spectral range, alternative laser technologies might be better adapted provided that a freedom on spectral bandwidths exists and does not influence pulse duration. Such a system does exist: it is the case 


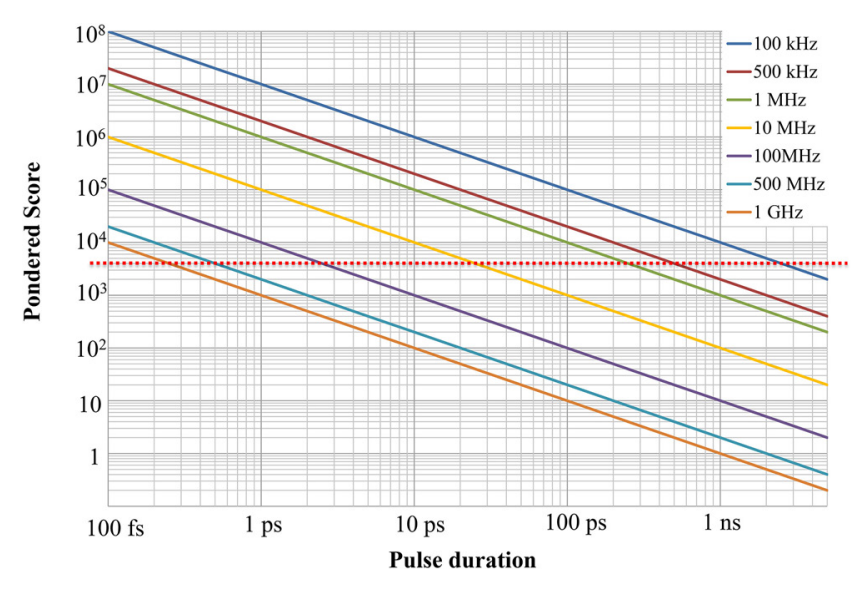

Figure 5. Pondered score as function of pulse duration and repetition rate. Horizontal red dashed line represents a single value of $P_{\mathrm{s}}$ which can be obtained thanks to several couples of $\{f, \tau\}$.

for example in ultra-wide band sources based on laser diodes broadened in optical fibers [128].

\subsection{Average power}

For the definition of the optimal average power, the question of sample safety must be considered. It is difficult to settle on a precise value, because the sample safety is different for each situation. It depends, for example, on the environment of the sample, its constitution and the excitation wavelength. In the literature, it is quite common to find average powers around a few tens of $\mathrm{mW}$ for resected samples. In the case of in vivo experiments, imaging in depth often requires a few hundreds of $\mathrm{mW}$ without significant tissue damage highlighted, thanks to the circulation of physiological flows. The precise definition of this value would need a complete study of the relation between image quality, depth of imaging, and photodamage or photodestruction as a function of the average power with fixed pulse duration and repetition rate. To build the identikit of an ideal excitation source for MPM, let us consider that the average power can be easily reduced thanks, for example, to neutral densities or beam splitters; no highest average power is defined.

Following the average powers presented in table 5, we can observe that it is usual to involve from few $\mathrm{mW}$ until few hundreds of $\mathrm{mW}$. Let us consider routine conditions where a spectral bandwidth $\Delta \lambda=10 \mathrm{~nm}$ is associated with an average power of $30 \mathrm{~mW}$, corresponding to $3 \mathrm{~mW} \mathrm{~nm}^{-1}$. By extrapolation, for a spectral bandwidth of $1400 \mathrm{~nm}$ (from $500 \mathrm{~nm}$ to $1.9 \mu \mathrm{m})$, the total average power of the corresponding source is about $4.2 \mathrm{~W}$, coupled with a microscope setup having unavoidable losses. An average power of $10 \mathrm{~W}$ uniformly spread over the whole spectral range is comfortable.

\subsection{Balance sheet of the optimal physical parameters of the excitation source}

$10 \mathrm{~W}\left(7 \mathrm{~mW} \mathrm{~nm}^{-1}\right), 2 \mathrm{MHz}, 100 \mathrm{fs}$

$500 \mathrm{~nm}-1.9 \mu \mathrm{m}$

$S=3.13 \times 10^{8}$

$P_{\text {s norm }}=200$

\subsection{An identikit more accessible technically}

Finally, femtosecond systems are the best adapted for MPM considering figure 4, which highlights that the majority of sources demonstrated for MPM in the literature are femtosecond and based on mode-locked technologies. But they are also the most expensive and complex technically.

With the goal of a democratization of multiphoton microscopes in labs, the choice of a cheaper solution, for example based on laser diodes, should not be neglected. Figure 4 shows that some picosecond sources can be as efficient as femtosecond systems. Equivalent efficiencies for MPM of very different lasers can be evaluated thanks to a basic calculation from equation (5), illustrated in figure 5. It represents the evolution of $P_{\mathrm{s}}$ as a function of pulse duration between $100 \mathrm{fs}$ and 5 $\mathrm{ns}$, and for different repetition rates between $100 \mathrm{kHz}$ and 1 $\mathrm{GHz}$. It shows that for different pairings of repetition rate and pulse duration, the same value of pondered score can be obtained, illustrated in figure 5 by the horizontal red dashed line corresponding to $P_{\mathrm{s}}=3.10^{3}$. This value exists for the paired values of $\{f, \tau\}:\{100 \mathrm{kHz}, 2.5 \mathrm{~ns}\},\{500 \mathrm{kHz}, 500 \mathrm{ps}\}$, $\{1 \mathrm{MHz}, 250 \mathrm{ps}\},\{10 \mathrm{MHz}, 25 \mathrm{ps}\},\{100 \mathrm{MHz}, 2.5 \mathrm{ps}\}$, $\{500 \mathrm{MHz}, 500 \mathrm{fs}\},\{1 \mathrm{GHz}, 250 \mathrm{fs}\}$.

Before reaching the perfect excitation source for MPM, a more accessible identikit can be proposed. For example, an adapted excitation source for MPM might have these physical parameters:

\begin{tabular}{|c|}
\hline $5 \mathrm{~W}\left(4 \mathrm{~mW} \mathrm{~nm}^{-1}\right), 2 \mathrm{MHz}, 0.5 \mathrm{ps}$ \\
$600 \mathrm{~nm}-1.8 \mu \mathrm{m}$ \\
$S=0.78 \times 10^{8}$ \\
$P_{\mathrm{s} \text { norm }}=40$
\end{tabular}

\section{Conclusion}

MPM is an outstanding method employed in a large number of biomedical research works where the study of living cells, organs, organisms or samples at the micron scale is indispensable. Thanks to the concordance of two facts: (i) MPM being a solution to a problem and (ii) the technology involved being close to its maturity, several applicative areas in biomedical fields have already been improved or made possible thanks to MPM, being user-friendly with technical advantages and features delivering incomparable results. Despite this encouraging context, MPM has probably not yet reached its apogee: this microscopy technique is relatively infrequently applied in labs routinely using optical microscopy, compared to other techniques such as one-photon-confocal microscopy. The technological efforts required to achieve a totally completed tool are maybe not so numerous. To understand these points, two elements must be inventoried first: (i) the ins and outs of MPM for biological imaging and (ii) what technological evolutions have been already done in this domain. These fundamental starting elements have been developed in the present article. A limitation has thus been highlighted, linked to the excitation source usually implemented in MPM: it is well adapted but has spectral and temporal limitations and is very 
expensive-half the cost of a commercial multiphoton microscope derives from the excitation source: a titanium-doped sapphire (Ti: $\mathrm{Sa}$ ) laser.

In the literature, several tens of works have demonstrated the advantages of alternative excitation sources. Each of them has specific physical parameters: average power, pulse duration, repetition rate, excitation wavelength and spectral bandwidth. They are tested on different samples/ fluorophores and multiphoton processes. It is thus hard to know what excitation source is the best for MPM, and what parameter of comparison must be considered: image quality (blur and noise), sample safety, depth of imaging, number of imaging modalities, use of endogenous or exogenous fluorophores .... .

In this publication, a panorama of the excitation sources which have so far been demonstrated in the literature for MPM is presented. Then, and based on the original paper of W W Webb's team in 1990 about MPM, a comparison of these sources is proposed. Finally, with this method of comparison, an identikit for ideal excitation source for MPM is proposed, concluding on the ideal physical parameters of the excitation laser source for MPM:

- A repetition rate of $2 \mathrm{MHz}$

$-100 \mathrm{fs}$ to $0.5 \mathrm{ps}$ of pulse duration

- Several spectral bandwidths delivered simultaneously with tunable central wavelengths between $500 \mathrm{~nm}$ until $1.9 \mu \mathrm{m}$ and adjustable spectral widths

- An average power about $7 \mathrm{~mW} \mathrm{~nm}^{-1}$

Commercially, this ideal source does not exist yet, and maybe will never exist. But before fully reaching all of these ideal parameters, compromises could be found: longer pulse duration could be compensated by a slower repetition rate provided that the limits of the other parameters are respectedleaving the resulting excitation source nevertheless suitable for MPM.

\section{References}

[1] Vo-Dinh T 2003 Biomedical Photonics Handbook (Boca Raton, FL: CRC Press)

[2] Denk W, Strickler J H and Webb W W 1990 Two-photon laser scanning fluorescence microscopy Science 248 73-6

[3] Pawel J 2006 Handbook of Biological Confocal Microscopy 3rd edn (Berlin: Springer) pp 1-985

[4] Masters B R and So P T C 2001 Confocal microscopy and multi-photon excitation of human skin in vivo Opt. Express $82-10$

[5] So P T, Dong C Y, Masters B R and Berland K M 2000 Twophoton excitation fluorescence microscopy Annu. Rev. Biomed. Eng. 2 399-429

[6] Konig K 2000 Multiphoton microscopy in life sciences J. Microsc. 200 83-104

[7] Zipfel W, Williams R M and Webb W W 2003 Nonlinear magic: multiphoton microscopy in the biosciences Nat. Biotechnol. 21 1369-77

[8] Oheim M, Michael D J, Geisbauer M, Madsen D and Chow R H 2006 Principles of two-photon excitation fluorescence microscopy and other nonlinear imaging approaches Adv. Drug Deliv. Rev. 58 788-808
[9] Diaspro A, Chirico G and Collini M 2005 Two-photon fluorescence excitation and related techniques in biological microscopy Q. Rev. Biophys. 38 97-166

[10] Ustione A and Piston D W 2011 A simple introduction to multiphoton microscopy J. Microsc. 243 221-6

[11] Masters B R and So P T C 2004 Antecedents of two-photon excitation laser scanning microscopy Microsc. Res. Tech. $633-11$

[12] Piston D W 1999 Imaging living cells and tissues by twophoton excitation microscopy Cell Biol. 9 66-9

[13] Masters B R, So P T C, Kim K H, Buehler C and Gratton E 1999 Multiphoton excitation microscopy, confocal microscopy, and spectroscopy of living cells and tissues; functional metabolic imaging of human skin in vivo Multiphoton Excitation Microscopy (Methods in Enzymology vol 307) (New York: Academic) ch 29 pp 513-36

[14] Denk W, Piston D W and Webb W W 1995 Two-photon molecular excitation in laser-scanning microscopy Handbook of Biological Confocal Microscopy ed J Pawley (New York: Plenum)

[15] Squier J and Muller M 2001 High resolution nonlinear microscopy: A review of sources and methods for achieving optimal imaging Rev. Sci. Instrum. 72 2855-67

[16] Girkin J M 2003 Optical physics enables advances in multiphoton imaging J. Phys. D: Appl. Phys. 36 250-8

[17] Girkin J M and McConnell G 2005 Advances in laser sources for confocal and multiphoton microscopy Microsc. Res. Tech. 67 8-14

[18] Xu C and Wise F 2013 Recent advances in fibre lasers for nonlinear microscopy Nat. Photon. 7 875-82

[19] Wise F 2013 Laser for nonlinear microscopy Cold Spring Harb. Protoc. (Cold Spring Harbor: CSHL Press) pp 192-9

[20] Young M D, Field J J, Sheetz K E, Bartels R A and Squier J 2015 A pragmatic guide to multiphoton microscope design $7276-378$

[21] Mohler W, Millard A C and Campagnola P J 2003 Second harmonic generation imaging of endogenous structural proteins Methods 29 97-109

[22] Campagnola P J and Loew L M 2003 Second-harmonic imaging microscopy for visualizing biomolecular arrays in cells, tissues and organisms Nat. Biotechnol. 21 1356-60

[23] Filippidis G, Kouloumentas C, Kapsokalyvas D, Voglis G, Tavernarakis N and Papazoglou T G 2005 Imaging of Caenorhabditis elegans samples and sub-cellular localization of new generation photosensitizers for photodynamic therapy, using non-linear microscopy J. Phys. D: Appl. Phys. 38 2625-32

[24] Ogilvie J P, Débarre D, Solinas X, Martin J L, Beaurepaire E and Joffre M 2006 Use of coherent control for selective two-photon fluorescence microscopy in live organisms Opt. Express 14 759-66

[25] Pastirk I, Dela Cruz J M, Walowicz C A, Lozovoy V V and Dantus M 2003 Selective two-photon microscopy with shaped femtosecond pulses Opt. Express 11 1695-701

[26] Tada J, Kono T, Suda A, Mizuno H, Miyawaki A, Midorikawa K and Kannari F 2007 Adaptively controlled supercontinuum pulse from a microstructure fiber for two-photon excited fluorescence microscopy Appl. Opt. 46 3023-30

[27] Hell S W, Bahlmann K, Schrader M, Soini A, Malak H, Gryczynski I and Lakowicz J R 1996 Three-photon excitation in fluorescence microscopy J. Biomed. Opt. 171-4

[28] Sinefeld D, Paudel H P, Ouzounov D, Bifano T G and Xu C 2015 Adaptive optics in multiphoton microscopy: comparison of two, three and four photon fluorescence Opt. Express 23 31472-83

[29] Mahou P, Zimmerley M, Loulier K, Matho K S, Labroille G, Morin X, Supatto W, Livet J, Debarre D and Beaurepaire E 
2012 Multicolor two-photon tissue imaging by wavelength mixing Nat. Methods 9 815-21

[30] Horton N G, Wang K, Kobat D, Clark C G, Wise F W, Schaffer C B and Xu C 2013 In vivo three-photon microscopy of subcortical structures within an intact mouse brain Nat. Photon. Lett. 7 205-9

[31] Wang K, Horton N G and Xu C 2013 Going deep: brain imaging with multi-photon microscopy Opt. Photonics News 24 32-9

[32] Markowicz P P, He S G and Prasad P N 2005 Direct fourphoton excitation of amplified spontaneous emission in a nonlinear organic chromophore Opt. Lett. 30 1369-71

[33] Zumbusch A, Holtom G R and Xie X S 1999 Threedimensional vibrational imaging by coherent anti-Stokes Raman scattering Phys. Rev. Lett. 82 4142-5

[34] Cheng J X, Jia Y K, Zheng G and Xie X S 2002 Laserscanning coherent anti-Stokes Raman scattering microscopy and applications to cell biology Biophys. J. 83 502-9

[35] Amor R, Norris G, Dempster J, Amos W B and McConnell G 2012 A compact instrument for adjusting laser beams to be accurately coincident and coaxial and its use in biomedical imaging using wave-mixed laser sources Rev. Sci. Instrum. 83083705

[36] Kano H and Hamaguchi H 2006 In vivo multi-nonlinear optical imaging of a living cell using a supercontinuum light source generated from a photonic crystal fiber $O p t$. Express 14 2798-804

[37] Freudiger C W, Min W, Saar B G, Lu S, Holtom G R, He C, Tsai J C, Kang J X and Xie X S 2008 Label-free biomedical imaging with high sensitivity by stimulated Raman scattering microscopy Science 322 1857-61

[38] Rigneault H and Gachet D 2014 Background-free coherent Raman imaging: the CARS and SRS contrast mechanisms Raman Imaging 168 347-72

[39] Sun Q, Li Y, He S, Situ C, Wu Z and Qu J Y 2014 Labelfree multimodal nonlinear optical microscopy reveals fundamental insights of skeletal muscle development Biomed. Opt. Express 5 158-66

[40] Débarre D, Supatto W, Pena A M, Fabre A, Tordjmann T, Combettes L, Schanne-Klein M C and Beaurepaire E 2006 Imaging lipid bodies in cells and tissues using thirdharmonic generation microscopy Nat. Methods 3 47-53

[41] Krmpot A J, Tserevelakis G J, Murić B D, Filippidis G and Pantelić D V 2013 3D imaging and characterization of microlenses and microlens arrays using nonlinear microscopy J. Phys. D: Appl. Phys. 46

[42] Renaud S, Weizhang K and McConnell G 2008 Characterization of microscope objective lenses from 1400 to $1650 \mathrm{~nm}$ to evaluate performance for long-wavelength nonlinear microscopy applications Microsc. Res. Tech. 71 517-20

[43] Shen Y R 1984 The Principles of Nonlinear Optics (New York: Wiley)

[44] Shen Y R 2003 The Principles of Nonlinear Optics (Hoboken, NJ: Wiley)

[45] Boyd R W 2003 Nonlinear Optics (New York: Academic)

[46] Goppert-Mayer M 1931 Uber Elementarakte mit zwei Quantensprungen Ann. Phys. 401 273-94

[47] Kaiser W, Garrett C G B and Wood D L 1961 Fluorescence and optical maser effects in $\mathrm{CaF}_{2}: \mathrm{Sm}++$ Phys. Rev. 123 766-76

[48] Developmental resource for biophysical imaging optoelectronics www.drbio.cornell.edu/cross_sections.html Cornell University

[49] Mütze J, Iyer V, Macklin J J, Colonell J, Karsh B, Petrasek Z, Schwille P, Looger L L, Lavis L D and Harris T D 2012 Excitation spectra and brightness optimization of twophoton excited probes Biophys. J. 102 934-44

[50] Heinze K G, Koltermann A and Schwille P 2000 Simultaneous two-photon excitation of distinct labels for dual-color fluorescence crosscorrelation analysis Proc. Natl Acad. Sci. 97 10377-82

[51] Xu C and Webb W W 1996 Measurement of two-photon excitation cross sections of molecular fluorophores with data from 690 to $1050 \mathrm{~nm}$ JOSA B 13 481-91

[52] Zipfel W R, Williams R M, Christie R, Yu Nikitin A, Hyman B T and Webb W W 2003 Live tissue intrinsic emission microscopy using multiphoton-excited native fluorescence and second harmonic generation Proc. Natl Acad. Sci. 100 7075-80

[53] Lakowicz J R 2006 Principles of Fluorescence Spectroscopy 3rd edn (Berlin: Springer)

[54] Sheppard C and Kompfner R 1978 Resonant scanning optical microscope Appl. Opt. 17 2879-82

[55] Freund I and Deutsch M 1986 Second-harmonic microscopy of biological tissue Opt. Lett. 11 94-6

[56] Mertz J and Moreaux L 2001 Second-harmonic generation by focused excitation in inhomogeneously distributed scatterers Opt. Commun. $196325-30$

[57] Burke K A, Dawes R P, Cheema M K, Van Hove A, Benoit D S W, Perry S W and Brown E 2015 Secondharmonic generation scattering directionality predicts tumor cell motility in collagen gels J. Biomed. Opt. 20051024

[58] Barad Y, Eisenberg H, Horowitz M and Silberg Y 1997 Nonlinear scanning laser microscopy by third harmonic generation Appl. Phys. Lett. 70 922-4

[59] Rigneault H and Andresen E 2012 Microscopy, fast and labelfree Nat. Photon. 6 802-3

[60] Djaker N, Marguet D and Rigneault H 2006 Microscopie Raman Stimulée (CARS) Principe et applications Medecine/Sciences 22 853-8

[61] Supatto W, Truong T V, Debarre D and Beaurepaire E 2011 Advances in multiphoton micrscopy for imaging embryos Curr. Opin. Genet. Dev. 21 538-48

[62] Sordillo L A, Pu Y, Pratavieira S, Budansky Y and Alfano R R 2014 Deep optical imaging of tissue using the second and third near-infrared spectral windows J. Biomed. Opt. 19056004

[63] Butko M T, Drobizhev M, Makarov N S, Reban A, Brinkman B C and Gleeson J G 2011 Simultaneous multipleexcitation multiphoton microscopy yields increased imaging sensitivity and specificity BMC Biotechnol. 2011 11-20

[64] Negrean A and Mansvelder H D 2014 Optimal lens design and use in laser-scanning microscopy Biomed. Opt. Express 5 1588-609

[65] Oheim M, Beaurepaire E, Chaigneau E, Mertz J and Charpak S 2001 Two-photon microscopy in brain tissue: parameters influencing the imaging depth $J$. Neurosci. Methods 111 29-37

[66] Gu M 1996 Resolution in three-photon fluorescence scanning microscopy Opt. Lett. 21 988-90

[67] Hell S W et al 2015 The 2015 super-resolution microscopy roadmap J. Phys. D: Appl. Phys. 48443001

[68] Dyba M, Klar T A, Jakobs S and Hell S W 2000 Ultrafast dynamics microscopy Appl. Phys. Lett. 77 597-9

[69] Flusberg B A, Cocker E D, Piyawattanametha W, Jung J C, Cheung E L M and Schnitzer M J 2005 Fiber-optic fluorescence imaging Nat. Methods 2 941-50

[70] Tang S, Jung W, McCormick D, Xie T, Su J, Ahn YC, Tromberg B J and Chen Z 2009 Design and implementation of fiber-based multiphoton endoscopy with microelectromechanical systems scanning J. Biomed. Opt. 14034005

[71] Huang L, Mills A K, Zhao Y, Jones D J and Tang S 2016 Miniature fiber-optic multiphoton microscopy system using frequency-doubled femtosecond Er-doped fiber laser Biomed. Opt. Express 7 1948-56 
[72] Flusberg B A, Jung J C, Cocker E D, Anderson E P and Schnitzer M J 2005 In vivo brain imaging using a portable $3.9 \mathrm{~g}$ two-photon fluorescence microendoscope Opt. Lett. 30 2272-4

[73] Straub M and Hell S W 1998 Fluorescence lifetime threedimensional microscopy with picosecond precision using a multifocal multiphoton microscope Appl. Phys. Lett. 731769

[74] Durst M E, Zhu G and Xu C 2008 Simultaneous spatial and temporal focusing in nonlinear microscopy Opt. Commun. 281 1296-805

[75] Wang K and Qiu P 2015 Optimal spectral filtering in soliton self-frequency shift for deep-tissue multiphoton microscopy J. Biomed. Opt. 202293065

[76] Rowlands C J, Park D, Bruns O T, Piatkevich K D, Fukumura D, Jain R K, Bawendi M G, Boyden E S and So P TC 2017 Wide-field three-photon excitation in biological samples Light Sci. Appl. 6 1-9

[77] Xu C, Zipfel W, Shear J B, Williams R M and Webb W W 1996 Multiphoton fluorescence excitation: new spectral windows for biological nonlinear microscopy Proc. Natl Acad. Sci. USA 93 10763-8

[78] Peyrot D A et al 2012 Development of a nonlinear fiber-optic spectrometer for human lung tissue exploration Biomed. Opt. Express 3 840-53

[79] Friedl P, Wolf K, Andrian U H and Harms G 2007 Biological second and third harmonic generation microscopy Curr. Protocols Cell Biol. 4

[80] Talamond P, Verdeil J-L and Conejero G 2015 Secondary metabolite localization by autofluorescence in living plant cells Molecules 20 5024-37

[81] Strupler M, Pena A M, Hernest M, Tharaux P L, Martin J L, Beaurepaires E and Schanne-Klei M C 2007 Second harmonic imaging and scoring of collagen in fibrotic tissues Opt. Express 15 4054-65

[82] Kirkpatrick D et al 2007 Endogenous optical biomarkers of ovarian cancer evaluated with multiphoton microscopy Cancer Epidermiol. Biomarkers Prev. 16 2048-57

[83] Odin C, Guilbert T, Alkilani A, Boryskina O P, Fleury V and Le Grand Y 2008 Collagen and myosin characterization by orientation field second harmonic microscopy Opt. Express 16 16151-65

[84] Kantelhardt S R, Leppert J, Krajewski J, Petkus N, Reusche E, Tronnier V M, Huttmann G and Giese A 2007 Imaging of brain and brain tumor specimens by time-resolved multiphoton excitation microscopy ex vivo Neuro Oncol. 9 103-12

[85] Najari B B et al 2012 Pilot study of the correlation of multiphoton tomography of ex vivo human testis with histology J. Urol. 188 538-43

[86] Hu W, Zhao G, Wang C, Zhang J and Fu L 2012 Nonlinear optical microscopy for histology of fresh normal and cancerous pancreatic tissues PLoS One 737962

[87] Chen Y, Chen J, Chen H, Hong Z, Zhu X, Zhuo S, Chen Y and Chen J 2014 Multiphoton microscopy as a diagnostic imaging modality for pancreatic neoplasms without hematoxylin and eosin stains J. Biomed. Opt. 19096008

[88] Hamzeh H, Lefort C, Pain F, Abi Haidar D 2015 Optimization and characterization of nonlinear excitation and collection through a gradient-index lens for high-resolution nonlinear endomicroscopy Optics Letters 40 808-4

[89] Brockman P, Bair C H, Barnes J C, Hess R V and Browell E 1986 Pulsed injection control of a titanium-doped sapphire laser Opt. Lett. 11 712-4

[90] Theer P, Hasan M T and Denk W 2003 Two-photon imaging to a depth of $1000 \mathrm{~mm}$ in living brains by use of a Ti: $\mathrm{Al}_{2} \mathrm{O}_{3}$ regenerative amplifier Opt. Lett. 28 1022-4

[91] Liu X, Svane A S, Laegsgaard J, Tu H, Boppart S A and Turchinovich D 2016 Progress in Cherenkov femtosecond fiber lasers J. Phys. D: Appl. Phys. 49023001
[92] Szipöcs R, Ferencz K, Spielmann C and Krausz F 1994 Chirped multilayer coatings for broadband dispersion control in femtosecond lasers Opt. Lett. 19 201-3

[93] Tang S, Chen Z, Tempea G and Tromberg B J 2006 Effect of pulse duration on two-photon excited fluorescence and second harmonic generation in nonlinear optical microscopy J. Biomed. Opt. 11020501

[94] Lefort C, Kalashyan M, Ducourthial G, Mansuryan T, O'Connor R P and Louradour F 2014 Sub-30 fs pulse compression and pulse shaping at the output of a $2 \mathrm{~m}$-long optical fiber in the near-infrared range JOSA B 31 2317-24

[95] Mojzisova H and Vermot J 2011 When multiphoton microscopy sees near infrared Curr. Opin. Genet. Dev. 21 549-57

[96] Tragardh J, Robb G, Amor R, Amos W B, Dempster J and McConnell G 2015 Exploration of the two-photon excitation spectrum of fluorescent dyes at wavelengths below the range of the Ti:Sapphire laser J. Microsc. $259210-8$

[97] Andresen V, Alexander S, Heupel W M, Hirschberg M, Hoffman R M and Friedl P 2009 Infrared multiphoton microscopy: subcellular-resolved deep tissue imaging Curr. Opin. Biotechnol. 20 54-62

[98] Wang C, Qiao L, He F, Chenng Y and Xu Y 2011 Extension of imaging depth in two-photon fluorescence microscopy using a long-wavelength high-pulse-energy femtosecond laser source J. Microsc. 243 179-83

[99] Wokosiny L D, Centonzey V E, Crittendenz S and White J 1996 Three-photon excitation fluorescence imaging of biological specimens using an all-solid-state laser Bioimaging 4 208-14

[100] Tang S, Liu J, Krasieva T B, Chen Z and Tromberg B J 2009 Developing compact multiphoton systems using femtosecond fiber lasers J. Biomed. Opt. Lett. 14030508

[101] Svoboda K, Denk W, Knox W H and Tsuda S 1996 Twophoton-excitation scanning microscopy of living neurons with a saturable Bragg reflector mode-locked diodepumped Cr:LiSrAlFl laser Opt. Lett. 21 1411-3

[102] Chen I H, Chu S W, Sun C K, Cheng P C and Lin B L 2002 Wavelength dependent damage in biological multiphoton confocal microscopy: a micro-spectroscopic comparison between femtosecond Ti:sapphire and Cr:forsterite laser sources vol $34 \mathrm{pp} 1251-66$

[103] McConnell G and Riis E 2004 Photonic crystal fibre enables short-wavelength two-photon laser scanning fluorescence microscopy with fura-2 Phys. Med. Biol. 49 4757-63

[104] Chan M C, Liu T M, Tai S P and Sun C K 2005 Compact fiber-delivered $\mathrm{Cr}$ :forsterite laser for nonlinear light microscopy J. Biomed. Opt. 10054006

[105] Sakadžić S, Demirbas U, Mempel T R, Moore A, Ruvinskaya S, Boas D A, Sennaroglu A, Kartner F X and Fujimoto J G 2008 Multi-photon microscopy with a low-cost and highly efficient $\mathrm{Cr}$ :LiCAF laser Opt. Express 16 20848-63

[106] Antal P G and Szipocs R 2012 Tunable, low-repetition-rate, cost-efficient femtosecond Ti:sapphire laser for nonlinear microscopy Appl. Phys. B 107 17-22

[107] Rehbinder J, Bruckner L, Wipfler A, Buckup T and Motzkus M 2014 Multimodal nonlinear optical microscopy with shaped $10 \mathrm{fs}$ pulses $O p t$. Express 22 28790-7

[108] Lefort C, Hamzeh H, Louradour F, Pain F and Abi Haidar D 2015 Characterization, comparison, and choice of a commercial double-clad fiber for nonlinear endomicroscopy J. Biomed. Opt. 19076005

[109] Rohrbacher A, Olarte O E, Villamaina V, Loza-Alvarez P and Resan B 2017 Multiphoton imaging with 
blue-diode-pumped SESAM-modelocked Ti:sapphire oscillator generating $5 \mathrm{~nJ} 82 \mathrm{fs}$ pulses Opt. Express 25 10684-77

[110] Balu M, Saytashev I, Hou J, Dantus M and Tromberg B J 2015 Sub-40 fs, $1060 \mathrm{~nm}$ Yb-fiber laser enhances penetration depth in nonlinear optical microscopy of human skin J. Biomed. Opt. 20120501

[111] Chen H W, Haider Z, Lim J K, Xu S, Yang Z, Kartner F X and Chang G 20133 GHz, Yb-fiber laser-based, few-cycle ultrafast source at the Ti:sapphire laser wavelength $O p t$. Lett. 38 4927-30

[112] Zhang Z, Popa D, Wittwer V J, Milana S, Hasan T, Jiang Z, Ferrari A C and Ilday F O 2015 All-fiber nonlinearity- and dispersion-managed dissipative soliton nanotube modelocked laser Appl. Phys. Lett. 107241107

[113] Oshima Y, Horiuch H, Honkura N, Hikita A, Ogata T, Miura H and Imamura T 2014 Intravital multiphoton fluorescence imaging and optical manipulation of spinal cord in mice, using a compact fiber laser system Laser Surg. Med. 46 563-72

[114] Millard A C, Wieman P W, Fittinghoff D N, Wilson K R, Squier J A and Muller M 1999 Third-harmonic generation microscopy by use of a compact, femtosecond fiber laser source Appl. Opt. 38 7393-7

[115] Kieu K, Mehravar S, Gowda R, Norwood R A and Peyghambarian N 2013 Label-free multi-photon imaging using a compact femtosecond fiber laser mode-locked by carbon nanotube saturable absorber vol 4 pp 2187-95

[116] Harpel K, Baker R D, Amirsolaimani B A, Mehravar S, Vagner J, Matsunaga T O, Banerjee B and Kieu K 2013 Imaging of targeted lipid microbubbles to detect cancer cells using third harmonic generation microscopy J. Biomed. Opt. 7 2849-59

[117] Isobe K, Watanabe W, Matsunaga S, Higashi T, Fukui K and Itoh K 2005 Multi-spectral two-photon excited fluorescence microscopy using supercontinuum light source Japan. J. Appl. Phys. 44 167-9

[118] Mc Connell G 2005 Sequential confocal and multiphoton laser scanning microscopy using a single photonic crystal fibre based light source Appl. Phys. B 81 783-6

[119] Unruh J R, Price E S, Gagliano Molla R, Stehno-Bittek L, Johnson C K and Hui R 2006 Two-photon microscopy with wavelength switchable fiber laser excitation Opt. Express 14 9825-31

[120] von Vacano B, Buckup T and Motzkus M 2006 In situ broadband pulse compression for multiphoton microscopy using a shaper-assisted collinear SPIDER Opt. Lett. 31 1154-6

[121] Isobe K, Suda A, Tanaka M, Kannari F, Kawano H, Mizuno H, Miyawaki A and Midorikawa K 2008 Fourier-transform spectroscopy combined with a 5 fs broadband pulse for multispectral nonlinear microscopy Phys. Rev. A 77063832

[122] Li D, Zheng W and Qu J Y 2009 Two-photon autofluorescence microscopy of multicolor excitation $O p t$. Lett. 34 202-4

[123] Liu Y, Tu H, Benalcazar W A, Chaney E J and Boppart S A 2012 Multimodal nonlinear microscopy by shaping a fiber supercontinuum from 900 to $1160 \mathrm{~nm}$ IEEE J. Sel. Top. Quantum Electron. 18 1209-14

[124] Liang X and Fu L 2013 Enhanced self-phase modulation enables a 700-900 nm linear compressible continuum for multicolor two-photon microscopy IEEE J. Sel. Top. Quantum Electron. 206800108

[125] Chan M-C, Lien C-H, Lu J-Y and Lyu B-H 2014 High power NIR fiber-optic femtosecond Cherenkov radiation and its application on nonlinear light microscopy Opt. Express 22 9498-507
[126] Cadroas P et al 2017 All-fiber femtosecond laser providing $9 \mathrm{~nJ}, 50 \mathrm{MHz}$ pulses at $1650 \mathrm{~nm}$ for three-photon microscopy J. Opt. 19065506

[127] Bewersdorf J and Hell S W 1997 Picosecond pulsed twophoton imaging with repetition rates of 200 and $400 \mathrm{MHz}$ J. Microsc. 191 28-38

[128] Jenei A, Kirsch A K, Subramaniam V, Arndt-Jovin D J and Jovin T M 1999 Picosecond multiphoton scanning nearfield optical microscopy vol 76 pp 1092-100

[129] Kuramoto M, Kitajima N, Guo H, Furushima Y, Ikeda M and Yokoyama H 2007 Two-photon fluorescence bioimaging with an allsemiconductor laser picosecond pulse source Opt. Lett. 32 2726-8

[130] Yokoyama H, Guo H, Yoda T, Takashima K, Sato K, Taniguchi $\mathrm{H}$ and Ito $\mathrm{H} 2006$ Two-photon bioimaging with picosecond optical pulses from a semiconductor laser Opt. Express 14 3467-71

[131] Palero J A, Boer V O, Vijverberg J C and Gerritsen H C 2005 Short-wavelength two-photon excitation fluorescence microscopy of tryptophan with a photonic crystal fiber based light source Opt. Express 13 5363-8

[132] Yokoyama H, Sato A, Guo H C, Sato K, Mure M and Tsubokawa H 2008 Nonlinear microscopy optical-pulse sources based on mode-locked semiconductor lasers Opt. Express 10 17752-8

[133] Tao W, Bao H and Gu M 2011 Enhanced two-channel nonlinear imaging by a highly polarized supercontinuum light source generated from a nonlinear photonic crystal fiber with two zero-dispersion wavelengths J. Biomed. Opt. 16056010

[134] Kawakami R, Sawada K, Sato A, Hibi T, Kozawa Y, Sato S, Yokoyama H and Nemoto T 2013 Visualizing hippocampal neurons with in vivo two-photon microscopy using a $1030 \mathrm{~nm}$ picosecond pulse laser $S c i$. Rep. 31014

[135] Kawakami R, Sawada K, Kusama Y, Fang Y-C, Kanazawa S, Kozawa Y, Sato S, Yokoyama H and Nemoto T 2015 In vivo two-photon imaging of mouse hippocampal neurons in dentate gyrus using a light source based on a high-peak power gains-witched laser diode Biomed. Opt. Express 6 891-901

[136] Niederriter R D, Ozbay B N, Futia G L, Gibson E A and Gopinath J T 2017 Compact diode laser source for multiphoton biological imaging Biomed. Opt. Express 8 315-22

[137] Segawa H, Okuna M, Leproux P, Couderc V, Ozawa T and Kano H 2015 Multimodal imaging of living cells with multiplex coherent anti-stokes Raman scattering (CARS), third-order sum frequency generation (TSFG) and twophoton excitation fluorescence (TPEF) using a nanosecond white-light laser source Anal. Sci. 31 1-7

[138] Lefort C, O’Connor R P, Blanquet V, Magnol L, Kano H, Tombelaine V, Lévêque P, Couderc V and Leproux P 2016 Multicolor multiphoton microscopy based on a nanosecond supercontinuum laser source $J$. Biophotonics $9709-14$

[139] Karpf S, Eibl M, Sauer B, Reinholz F, Huttmann G and Huber R 2016 Two-photon microscopy using fiber-based nanosecond excitation Biomed. Opt. Express 7 2432-40

[140] Florin E L, Horber J K H and Stelzer E H K 1996 Highresolution axial and lateral position sensing using twophoton excitation of fluorophores by a continuous-wave Nd:YAG laser Appl. Phys. Lett. 69 446-8

[141] Hell S H, Booth M, Wilms S, Schnetter C M, Kirsch A K, Arndt-Jovin D J and Jovin T M 1998 Two-photon nearand far-field fluorescence microscopy with continuouswave excitation Opt. Lett. 23 1238-40 
[142] Hou X and Cheng W 2011 Single-molecule detection using continuous wave excitation of two-photon fluorescence Opt. Lett. 36 3185-7

[143] Uzunbajakava N and Otto C 2003 Combined Raman and continuous-wave-excited two-photon fluorescence cell imaging Opt. Lett. 28 2073-5

[144] Zhang Z X, Sonek G J, Wei X B, Sun C, Berns M W and Tromberg B J 1999 Cell vialbility and DNA denaturation measurements by two-photon fluorescence excitation in CX Al:GaAs diode laser optical traps J. Biomed. Opt. 4 256-9
[145] Tirri M, Vaarno J, Soini J T and Hanninen P 2003 Low cost lasers challenge ultrafast systems in two-photon excitation application Opto-Electron. Rev. 11 39-44

[146] Podgorski K and Ranganathan G 2016 Brain heating during multi-photon microscopy J. Neurophysiol. 116 1012-23

[147] Hopt A and Neher E 2001 Highly nonlinear photodamage in two-photon fluorescence microscopy Biophys. $J$. 80 2029-36

[148] Tauer U 2002 Advantages and risks of multiphoton microscopy in physiology Exp. Physiol. 87 709-14 